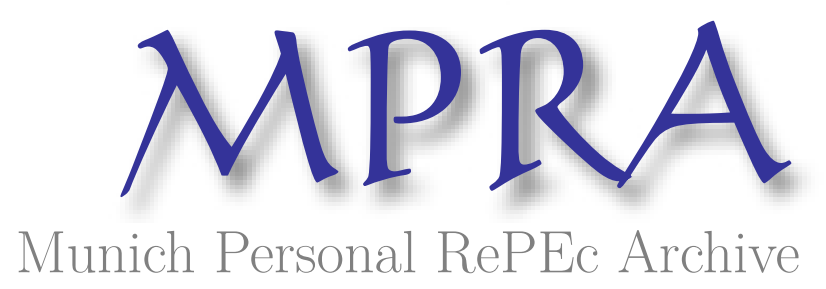

\title{
Using "opposing responses" and relative performance to distinguish empirically among alternative models of promotions
}

DeVaro, Jed

California State University, East Bay

2011

Online at https://mpra.ub.uni-muenchen.de/35175/

MPRA Paper No. 35175, posted 03 Dec 2011 23:47 UTC 


\title{
Using “Opposing Responses" and Relative Performance To Distinguish Empirically Among Alternative Models of Promotions
}

\author{
by \\ Jed DeVaro* \\ Department of Management and Department of Economics \\ College of Business and Economics \\ California State University, East Bay \\ Hayward, CA 94542 \\ Phone: (510)885-3289 \\ E-mail: jed.devaro@ csueastbay.edu
}

November 15, 2011

\begin{abstract}
Applying a simultaneous-equations estimation approach that accounts for both worker and firm behavior, I show that six alternative promotion models can be empirically distinguished to a greater extent than previously thought. I show that classic tournaments, market-based tournaments, and performance standards can be sharply distinguished when promotions induce worker effort. I also show that market-based tournaments with effort choices can be sharply distinguished from those with human capital investments. A key insight is that an empirical test can be based on the "opposing responses" property whereby workers and firms adjust their choice variables in opposite directions when the stochastic component of worker performance changes. Finally, I propose a new approach - also requiring simultaneous equations - for empirically distinguishing between classic tournaments and market-based tournaments with human capital investments, showing that the two models differ in their predictions regarding the average wage between job levels.
\end{abstract}

JEL codes: M50, M51

\footnotetext{
* I am particularly grateful to Mike Wagner, Mike Waldman, and Jan Zábojník for e-mail exchanges that considerably developed this work. Other readers whose helpful feedback I gratefully acknowledge include Martin Farnham, Suman Ghosh, Mike Gibbs, Kaj Gittings, Oliver Gürtler, Fidan Ana Kurtulus, Ed Lazear, and Hideo Owan.
} 


\section{Introduction}

Promotions typically come with wage increases and with other features that workers desire. ${ }^{1}$ For this reason, the prospect of future promotion creates incentives for workers to take actions to increase their chances of promotion. Such actions are usually performance enhancing and thus desirable from the employer's perspective. ${ }^{2}$ This role of promotions as an incentives mechanism is one important consideration for the firm as it makes choices associated with the design and management of promotion systems. Another important consideration for the firm is optimal assignment of workers to jobs, which sometimes conflicts with the incentive-creating function of promotions as noted in Baker, Jensen, and Murphy (1988). The theoretical models that have been developed to shed light on these issues can be categorized by their assumptions about the nature of the job hierarchy, the choice variables of workers, and the extent to which the firm can pre-commit to compensation prizes given competitive pressure from other firms in the labor market. ${ }^{3}$ Distinguishing among these competing models empirically is difficult given that their testable implications overlap substantially. This difficulty motivates the present study.

In this paper I show that the core theoretical models in the promotions literature can be empirically distinguished to a greater extent than previously thought. As depicted in Figure 1, two broad classes of models are "internal promotion competitions" characterized by fixed job slots and "performance standards models" characterized by flexible job slots. A fixed-slot job hierarchy is one with a limited number of managerial positions. For example, consider a twolevel job hierarchy with one managerial position and two subordinate positions, so that only one subordinate can be promoted. This scarcity of managerial positions automatically creates a zerosum internal promotion competition between the two subordinates. In contrast, if managerial job slots are flexible rather than fixed, it is possible that both subordinates can be promoted to the

\footnotetext{
${ }^{1}$ Several papers that document the large wage increases that accompany promotions include Murphy (1985), Gerhart and Milkovich (1989), Lazear (1992), Main, O’Reilly, and Wade (1993), Baker, Gibbs, and Holmstrom (1994a,b), and McCue (1996).

${ }^{2}$ These actions may in some cases be unproductive or even destructive, as in the case of sabotage (e.g. Lazear 1989, Garvey and Swan 1992, Drago and Garvey 1998, Konrad 2000, Chen 2003, Kräkel 2005, and Gürtler 2008) or influence activity (e.g. Milgrom and Roberts 1988, Meyer, Milgrom, and Roberts 1992, Schaefer 1998, and Fairburn and Malcomson 2001).

${ }^{3}$ See Gibbons and Waldman (1999b), Lazear (1999), Prendergast (1999), Lazear and Oyer (2010), and Waldman (2010) for surveys.
} 
level of manager, as long as their individual performances exceed a "performance standard" as discussed in Gibbs $(1994,1996)$.

Internal promotion competitions can be further classified into "classic tournaments" and "market-based tournaments" - using the terminology of Waldman (2011) - according to the mechanism by which wage spreads between job levels are generated. In classic tournaments, as first articulated in Lazear and Rosen (1981), firms strategically set wage spreads ex ante with the aim of eliciting the desired worker behavior, which is usually an effort choice. In market-based tournaments, wage spreads arise ex post as the outcome of a competitive bidding process in which an employer raises a promoted worker's wage to prevent the worker from being raided by competing firms that interpret observed promotions as signals of worker ability. ${ }^{4}$ In such models, the worker's choice variable that affects performance (and thereby the promotion probability) is sometimes effort (as in Gibbs 1995 and Waldman 2011) and sometimes human capital investment (as in Zábojník and Bernhardt 2001 and Zábojník 2011). ${ }^{5}$

Performance standards models, like internal promotion competitions, can also be categorized by the worker's choice variable. Workers might choose an effort level as in Ghosh and Waldman (2010), a human capital investment as in Prendergast (1993), or nothing at all as in Waldman (1984a) and DeVaro and Waldman (2011). Performance standards models that do not incorporate any performance-enhancing worker choice do so as a simplification so as to focus on the assignment aspect of promotions as opposed to the incentive-creating aspect. Although some performance standards models do not incorporate a performance-enhancing worker choice, all tournament models incorporate such a choice. Thus, the two defining features of tournaments are fixed managerial job slots and endogenous, performance-enhancing worker choices. ${ }^{6}$

A large empirical literature has endeavored to test the implications of the theoretical models depicted in Figure 1. The bulk of this literature has focused on testing the implications of

\footnotetext{
${ }^{4}$ The seminal paper in this area is Waldman (1984a). Representative related papers include MacLeod and Malcomson (1988), Ricart i Costa (1988), Waldman (1990), Bernhardt (1995), Owan (2004), and Golan (2005).

${ }^{5}$ Recent evidence in DeVaro and Waldman (2011) using data from the firm first analyzed in Baker, Gibbs, and Holmstrom $(1994 a, b)$ suggests that in that firm the market-based wage-setting mechanism is empirically relevant. ${ }^{6}$ A model type not depicted in Figure 1 and that is less often seen in the literature is one with fixed managerial slots but without a worker choice variable. A recent example is DeVaro and Morita (2011).
} 
classic tournaments, and much of the evidence has been consistent with that theoretical model. ${ }^{7}$ The problem is that most of that evidence is also consistent with the other models in Figure 1. The near observational equivalence of these models is one of the most significant current challenges in the promotions literature and is the motivation for this study. The problem is well known. For example, Gibbs (1994) observes that the classic tournament model and the performance standards model are essentially observationally equivalent, and Waldman (2011) concludes that most of the existing evidence does not allow the classic and market-based tournament models to be distinguished. ${ }^{8}$

I show that two empirical tests are sufficient to distinguish among most of the six model types in Figure 1. The first test concerns whether promotions are determined by relative or absolute performance. When managerial job slots are scarce, this automatically creates internal promotion competitions among workers so that relative performance determines promotions. That is, an increase in worker i's performance, ceteris paribus, reduces worker j's chance of promotion, and vice versa. That would not be true with flexible managerial job slots in which any worker who performs sufficiently well can be promoted. In that case, absolute performance determines promotions, so that an increase in worker i's performance, ceteris paribus, has no effect on worker j's chance of promotion, and vice versa. This situation occurs in the performance standards models. Thus, one way to distinguish between the two main branches of Figure 1 is by investigating whether promotions are determined by relative performance or by absolute performance. The idea for such a test was mentioned in Gibbs (1994), and it was implemented empirically in DeVaro (2006a,b).

The second test is based on a property I refer to as "opposing responses". The basic idea is as follows. Consider a parameter, $\theta$, in one of the theoretical models in Figure 1. When the value of $\theta$ changes, this might induce adjustments in the choice variables of workers and the firm. If workers and the firm adjust their respective choice variables in opposite directions, the

\footnotetext{
${ }^{7}$ Representative empirical papers include O'Reilly, Main, and Crystal (1988), Ehrenberg and Bognanno (1990a,b), Lambert, Larcker, and Weigelt (1993), Main, O'Reilly and Wade (1993), Knoeber and Thurman (1994), Eriksson (1999), Bognanno (2001), Audus, Barmby and Treble (2004), DeVaro (2006a,b), and Agrawal, Knoeber, and Tsoulouhas (2006).

${ }^{8}$ However, Waldman does argue that in the existing empirical literature there are some pieces of evidence that point in one direction or the other.
} 
opposing responses property holds. Otherwise, it does not. If the property holds in some of the models in Figure 1 but not in others, this creates the basis for an empirical test to distinguish among models. This approach requires the existence of a parameter that is common to all models the researcher wishes to compare. That requirement is satisfied in the case of Figure 1, given that individual worker performance (or output) is typically modeled to include a stochastic component. I focus on the variance of that stochastic component, and henceforth I refer to that variance as $\theta$.

As an example of opposing responses, consider the classic tournament model which exhibits the property based on the following logic. Consider a two-player tournament with homogeneous workers in which the higher-performing worker wins the promotion, with the prize for promotion being the wage spread between the winner's job and the loser's job. Let $\theta$ denote the variance of the stochastic component of each worker's performance. When $\theta$ is large, worker performances (and therefore promotion outcomes) are largely random and are not affected much by the workers' (costly) effort choices. This decreases worker effort. Anticipating this, the firm increases the wage spread to "sweeten the pot" and offset the depressed incentives. In this context, the property of opposing responses arises from the fundamental assumption that firms strategically set wage spreads ex ante to induce effort.

If cross-sectional data on firms (or tournaments) are available that include information related to the choice variables of workers and firms, as well as information on $\theta$ across firms, the opposing responses property can be empirically tested. The primary obstacle to conducting this test is that data on $\theta$ are typically unavailable, given that $\theta$ is inherently difficult to measure. However, DeVaro (2006a,b) showed how to conduct the test for classic tournaments even in the absence of data on $\theta$, via an implied prediction on the sign of the cross-equation error correlation in a simultaneous-equations econometric model. Whereas those papers focused only on testing the predictions of the classic tournament model, in the present paper I determine whether the opposing responses property holds in each of the other five models in Figure 1. Thus, the present paper applies an existing empirical framework to answer a different set of questions. The new theoretical results of the present paper yield new interpretations of the empirical results from the earlier papers. Generating the new results concerning opposing responses requires either deriving 
new predictions from existing theoretical models or extending existing theoretical models in a way that will generate new predictions. This is because previous research has focused mainly on aspects of these models other than the responses of choice variables to shifts in $\theta$.

There are five new results. First, in the class of models in which promotions create incentives for effort, the opposing responses test and the relative-versus-absolute performance test together can distinguish among the three core promotions models in the literature, i.e. classic tournaments, market-based tournaments, and performance standards. Of particular interest is that the two types of tournament models (classic and market-based) can be sharply distinguished by the opposing responses property. Second, the two alternative ways to model market-based tournaments (i.e. worker effort choices or worker human capital investments) can also be sharply distinguished using opposing responses. Third, the performance standards models generally do not exhibit opposing responses, which offers another means (in addition to the relative-versus absolute performance test) of distinguishing the right branch of Figure 1 from classic tournaments. Fourth, opposing responses cannot distinguish classic tournaments with effort choices from market-based tournaments with human capital investments. Fifth, motivated by the fourth result, I derive a new empirical test that can distinguish between classic tournaments and market-based tournaments with human capital investments. The new test is based on the average wage between job levels instead of the wage spread between levels. ${ }^{9}$

After establishing the first four results, I explain how to conduct the empirical tests, showing that the empirical framework proposed in DeVaro (2006a,b) nests all of the models in Figure 1. Given the data that are typically available, the approach requires an empirical framework that simultaneously accounts for both worker and firm behavior via a system of equations. I then show that operationalizing the fifth new result requires a different systemsbased estimation approach. Such systems-based approaches are rarely seen in the promotions literature. Researchers instead focus on single-equation empirical models based either on firm behavior or on worker behavior in isolation but not on both simultaneously. An insight of this paper is that systems-based methods that simultaneously account for worker and firm behavior

\footnotetext{
${ }^{9}$ In a two-level job hierarchy where $\mathrm{W}_{\mathrm{m}}$ denotes the wage in the higher-level managerial job and $\mathrm{W}_{\mathrm{s}}$ denotes the wage in the lower-level subordinate job, the "average wage between job levels" is $\left(\mathrm{W}_{\mathrm{m}}+\mathrm{W}_{\mathrm{s}}\right) / 2$ whereas the "wage spread between levels" is $\mathrm{W}_{\mathrm{m}}-\mathrm{W}_{\mathrm{s}}$.
} 
offer a means of differentiating among alternative models of promotion that would otherwise appear observationally equivalent.

In related recent work, Waldman (2011) presents a detailed comparison of classic and market-based tournaments and provides the first evaluation of the extent to which the empirical evidence supports each model. Given that Waldman focuses only on the left branch of Figure 1, he does not consider the relative-versus-absolute performance test since it is unhelpful for his purpose. Furthermore, whereas I focus on the "opposing responses" prediction, Waldman focuses on other predictions such as those concerning the number of tournament contestants and the convexity of the wage structure within the firm. Although Waldman concludes that most of the evidence does not allow the two types of tournaments to be distinguished, he discusses some ways in which they might be distinguished, and I build on his discussion here. One result of the present paper is that market-based tournaments with endogenous effort choices (which are the primary market-based tournaments considered in Waldman 2011) can be sharply distinguished from classic tournaments using opposing responses. Another is that the new test I propose concerning the worker's expected wage allows market-based tournaments with human capital investments to be empirically distinguished from classic tournaments.

Given its focus on opposing responses to changes in $\theta$, this paper emphasizes the role of risk in the production environment in affecting worker and firm behavior and therefore observed outcomes. Although I focus on the effect of risk on worker decisions and wage spreads in the context of promotion schemes, the work relates in a natural way to a large literature that explores the effects of risk on the design of incentive contracts following original theoretical papers by Holmström (1979) and Shavell (1979). The literature that grew out of that work focuses on the observable implications (in terms of the compensation contracts employers choose) of variation in the degree of risk in the production environment and why the empirical literature has failed to consistently support a tradeoff between risk and incentive pay. Representative theoretical contributions include Zábojník (1996), Prendergast (2000, 2002), Baker and Jorgensen (2003), Raith (2003, 2008), Oyer (2004), Serfes (2005), and Rantakari (2008). Recent empirical tests 
include Foss and Laursen (2005), Oyer and Schaefer (2005), Wulf (2007), DeVaro and Kurtulus (2010), and DeVaro and Prasad (2011). ${ }^{10}$

\section{Classic Tournaments With Endogenous Effort Choices}

Most of the classic tournament literature builds on the two-player model of Lazear and Rosen (1981) which assumes a two-level job hierarchy with one managerial job at the top and two subordinate positions at the bottom. ${ }^{11}$ The performances of two identical, risk-neutral subordinates, denoted with subscripts $\mathrm{i}$ and $\mathrm{j}$, depend linearly on effort, e, and noise, $\mathrm{u}$, as follows: $P_{i}=e_{i}+u_{i}$ and $P_{j}=e_{j}+u_{j}$, where $u_{i}$ and $u_{j}$ are distributed independently, symmetrically, and identically with variance $\theta$. The firm observes which subordinate has the higher performance and promotes that worker to the managerial position, retaining the other as a subordinate. Due to the fixity of the job slots, this promotion rule implies that promotions are based on relative performance.

Let $\mathrm{W}_{\mathrm{m}}$ and $\mathrm{W}_{\mathrm{s}}$ denote the wages in the managerial and subordinate jobs, respectively, where $\mathrm{W}_{\mathrm{m}}>\mathrm{W}_{\mathrm{s}}$. Both wages are chosen by the firm ex ante to elicit the optimal effort choices of subordinates. After observing $\mathrm{W}_{\mathrm{m}}$ and $\mathrm{W}_{\mathrm{s}}$, subordinate $\mathrm{i}$ chooses $\mathrm{e}_{\mathrm{i}}$ to maximize expected utility, i.e. $\mathrm{pW}_{\mathrm{m}}+(1-\mathrm{p}) \mathrm{W}_{\mathrm{s}}-\mathrm{C}\left(\mathrm{e}_{\mathrm{i}}\right)$, where $\mathrm{p}$ is the probability that $\mathrm{i}$ wins (i.e. that $\left.\mathrm{P}_{\mathrm{i}}>\mathrm{P}_{\mathrm{j}}\right)$, and $\mathrm{C}(\mathrm{e})$ is a cost function for which $\mathrm{C}(0)=0, \mathrm{C}^{\prime}(0)=0, \mathrm{C}^{\prime}(\mathrm{e})>0$ for $\mathrm{e}>0$, and $\mathrm{C}^{\prime \prime}(\mathrm{e})$ for $\mathrm{e}>0$. Worker $\mathrm{j}$ 's problem is symmetric. The first-order condition defining worker $i$ 's optimal effort, $e_{i}{ }^{*}$, is: $\left(\mathrm{W}_{\mathrm{m}}-\mathrm{W}_{\mathrm{s}}\right) \partial \mathrm{p} / \partial \mathrm{e}_{\mathrm{i}}^{*}-\mathrm{C}^{\prime}\left(\mathrm{e}_{\mathrm{i}}^{*}\right)=0$

The probability that subordinate $i$ wins is $p=G\left(e_{i}-e_{j}\right)$ where $G$ is the cumulative distribution function for $\mathrm{u}_{\mathrm{j}}-\mathrm{u}_{\mathrm{i}}$, and $\partial \mathrm{p} / \partial \mathrm{e}_{\mathrm{i}}=\mathrm{g}\left(\mathrm{e}_{\mathrm{i}}-\mathrm{e}_{\mathrm{j}}\right)$. Symmetric equilibrium implies $\mathrm{e}_{\mathrm{i}}{ }^{*}=\mathrm{e}_{\mathrm{j}}{ }^{*}$, so the firstorder condition can be rewritten as: $\left(\mathrm{W}_{\mathrm{m}}-\mathrm{W}_{\mathrm{s}}\right) \mathrm{g}(0)=\mathrm{C}^{\prime}\left(\mathrm{e}^{*}\right)$. Two implications of this condition are worth noting. First, $\partial \mathrm{e}^{*} / \partial\left(\mathrm{W}_{\mathrm{m}}-\mathrm{W}_{\mathrm{s}}\right)>0$. Second, $\partial \mathrm{e}^{*} / \partial \mathrm{g}(0)>0$, which implies $\partial \mathrm{e}^{*} / \partial \theta<0$.

\footnotetext{
${ }^{10}$ Earlier empirical studies include Rao (1971), Anderson and Schmittlein (1984), Lambert and Larcker (1987), Kawasaki and McMillan (1987), Norton (1988), Martin (1988), John and Weitz (1989), Leffler and Rucker (1991), Allen and Lueck (1992), Lafontaine (1992), Garen (1994), Yermack (1995), Aggarwal and Samwick (1999), Core and Guay (1999), Conyon and Murphy (2000), Ackerberg and Botticini (2002), Mengistae and Xu (2004).

${ }^{11}$ Representative theoretical papers on classic tournaments include Green and Stokey (1983), Nalebuff and Stiglitz (1983), Malcomson (1984), Mookherjee (1984), O'Keeffe, Viscusi, and Zeckhauser (1984), Rosen (1986), Lazear (1989), Meyer (1991,1992), Chan (1996), Waldman (2003), and Tsoulouhas, Knoeber, and Agrawal (2007).
} 
The firm chooses $\mathrm{W}_{\mathrm{m}}$ and $\mathrm{W}_{\mathrm{s}}$ to maximize expected profit, $\mathrm{E}(\pi)$, subject to incentive compatibility and participation constraints, yielding the following first-order conditions in which the output price is normalized to 1 :

$\partial \mathrm{E}(\pi) / \partial \mathrm{W}_{\mathrm{m}}=\left(1-\mathrm{C}^{\prime}(\mathrm{e})\right) \partial \mathrm{e} / \partial \mathrm{W}_{\mathrm{m}}=0$ and $\partial \mathrm{E}(\pi) / \partial \mathrm{W}_{\mathrm{s}}=\left(1-\mathrm{C}^{\prime}(\mathrm{e})\right) \partial \mathrm{e} / \partial \mathrm{W}_{\mathrm{s}}=0$.

These and the worker's first-order condition together imply $\mathrm{W}_{\mathrm{m}}-\mathrm{W}_{\mathrm{s}}=1 / \mathrm{g}(0)$.

Note that $\partial\left(\mathrm{W}_{\mathrm{m}}-\mathrm{W}_{\mathrm{s}}\right) / \partial \mathrm{g}(0)<0$, implying $\partial \mathrm{S}^{*} / \partial \theta>0$ where $\mathrm{S}^{*}$ denotes the equilibrium spread.

Given that $\left(\mathrm{W}_{\mathrm{m}}-\mathrm{W}_{\mathrm{s}}\right) \mathrm{g}(0)=1$, any change in $\mathrm{g}(0)$ induced by a change in $\theta$ is offset by a change

in the spread. Intuitively, the firm increases the generosity of the prize to offset the depressed incentives created by an increase in the importance of luck in determining performance. ${ }^{12}$

To summarize, there are two important points of this section regarding classic tournaments. First, promotions are determined by relative performance. Second, $\partial \mathrm{e}^{*} / \partial \theta<0$ and $\partial \mathrm{S}^{*} / \partial \theta>0$ so that the choice variables of the workers and the firm are adjusted in opposite directions when $\theta$ changes. This property of opposing responses arises naturally from the model's fundamental structure. It does not rely on distributional assumptions (other than symmetry) or on functional form assumptions other than the usual assumptions about $\mathrm{C}(\mathrm{e})$. It does, however, require that workers be roughly homogeneous in ability. ${ }^{13}$ Note that $\mathrm{e}^{*}$ remains unchanged in response to changes in $\theta$, given that the effects of changes in $\theta$ on $g(0)$ and the spread are exactly offsetting. Thus, when we say that one requirement of opposing responses is that $\mathrm{e}^{*}$ decrease in response to an increase in $\theta$, we mean holding the spread constant.

\section{Performance Standards With Endogenous Worker Effort}

Gibbs $(1994,1996)$ argues that there are good reasons for firms to use performance standards rather than tournaments to make promotion decisions. As seen in Figure 1, such

\footnotetext{
${ }^{12}$ Note that the result that the firm chooses the wage spread that yields the first-best level of effort relies on the assumption that workers are risk neutral. If the workers were risk averse then the employer would find it optimal to partially insure workers against income risk by choosing a smaller wage spread, which in turn results in an equilibrium effort level below the first best. However, even in this case the qualitative result of interest continues to hold in that increases in $\theta$ induce the employer to increase the wage spread.

${ }^{13}$ Tournaments with heterogeneous contestants are considered in Lazear and Rosen (1981) and O'Keeffe, Viscusi and Zeckhauser (1984) and in the empirical analysis of Levy and Vukina (2004). Worker effort depends on $g\left(e_{i}-\right.$ $e_{j}$ ), where $e_{i}-e_{j}$ is zero when contestants are homogeneous in ability but potentially nonzero when contestants are heterogeneous in ability. In the latter case, an increase in noise may increase $g\left(e_{i}-e_{j}\right)$ and equilibrium effort. Intuitively, consider the problem from the standpoint of the less able of two heterogeneous competitors. If there is little noise, the worker has virtually no chance of winning, so incentives to exert costly effort are low, whereas a significant amount of noise brings that worker back into the race and increases incentives to exert effort.
} 
schemes are characterized by flexible job slots, so that all workers whose performance exceeds a fixed standard get promoted. This implies that promotions are determined by absolute performance. A seminal model of this type is Waldman (1984a), which was recently extended in DeVaro and Waldman (2011). ${ }^{14}$ In that framework, young workers are hired into the subordinate job in the first period. A worker's first-period output is observed by his own employer but not by competing employers. On the basis of that observation, the worker's employer decides whether to promote the worker in the second period or to retain the worker in the subordinate job. In either case, competing firms observe the worker's second-period job assignment, interpreting this as a signal of the worker's ability. Competing firms make wage offers to the worker on the basis of this job assignment. In equilibrium the worker remains with the original employer, and promoted workers (who are thought to be of high ability in the eyes of competing firms) receive a wage increase sufficient to prevent them from being raided by competing firms.

Recall that the property of opposing responses requires $\partial \mathrm{e}^{*} / \partial \theta<0$ and $\partial \mathrm{S}^{*} / \partial \theta>0$. In performance standards models such as Waldman (1984a) and DeVaro and Waldman (2011), the first of these conditions fails in a trivial sense given that there are no endogenous effort choices in the model, and thus no incentives. Thus, this framework does not exhibit opposing responses and neither does any other performance standards model that omits worker choices. But given that effort choices are omitted from these models primarily to simplify the analysis, the more interesting cases to consider are those in which worker effort choices are incorporated into the model. One such example is Ghosh and Waldman (2010). Although that analysis did not consider the effect of $\theta$ on either $\mathrm{e}^{*}$ or $\mathrm{S}^{*}$, I show below that it yields the result $\partial \mathrm{S}^{*} / \partial \theta=0$. To facilitate a precise discussion in this section and the next, it is helpful to reproduce the model here. ${ }^{15}$ At the start of period 1 it is common knowledge that each worker's innate ability, $\mathrm{A}_{\mathrm{i}}$, is $\mathrm{a}_{\mathrm{H}}$ with probability $\rho$ and $a_{L}$ with probability $1-\rho$, where $0<a_{L}<a_{H}$. The worker's effective ability in period $\mathrm{t}, \eta_{\mathrm{it}}$, is $\eta_{\mathrm{i} 1}=\mathrm{A}_{\mathrm{i}}$ and $\eta_{\mathrm{i} 2}=\mathrm{kA}$, where $\mathrm{k}>1$ represents general human capital.

\footnotetext{
${ }^{14}$ Another influential model of this type is Gibbons and Waldman (1999a) and the related analysis in Gibbons and Waldman (2006). These models assume symmetric learning, i.e. information about worker ability is revealed to all firms in the labor market at the same rate. In contrast, in models such as Waldman (1984a) and its various extensions, learning is asymmetric in that a worker's current employer observes the worker's productivity more accurately than competing employers do.

${ }^{15}$ The presentation here is abbreviated, with some details omitted and some changes in notation. Refer to the original paper for a more complete treatment.
} 
Subordinate i produces period-1 output of $\mathrm{y}_{\mathrm{is} 1}=\mathrm{d}_{\mathrm{s}}+\mathrm{c}_{\mathrm{s}}\left(\eta_{\mathrm{i} 1}+\mathrm{e}_{\mathrm{i} 1}+\mathrm{u}_{\mathrm{i} 1}\right)$, where the subscript 1 denotes time and the subscript " $\mathrm{s}$ " denotes subordinate, e is the effort choice, and $\mathrm{u}$ is a mean-zero, normally-distributed stochastic term with variance $\theta$. In period 2 , worker i's output in the managerial job is $\mathrm{y}_{\mathrm{im} 2}=(1+\mathrm{f})\left[\mathrm{d}_{\mathrm{m}}+\mathrm{c}_{\mathrm{m}}\left(\eta_{\mathrm{i} 2}+\mathrm{e}_{\mathrm{i} 2}+\mathrm{u}_{\mathrm{i} 2}\right)\right]$ whereas the same worker's output in the subordinate job is $y_{i s 2}=(1+f)\left[d_{s}+c_{s}\left(\eta_{i 2}+e_{i 2}+u_{i 2}\right)\right]$, where $f=F \geq 0$ if the worker remains with the original employer in the second period and $\mathrm{f}=0$ if the worker switches employers, so that $\mathrm{f}$ captures firm-specific human capital. As in Rosen (1982) and Waldman (1984b), $0<\mathrm{c}_{\mathrm{s}}<\mathrm{c}_{\mathrm{m}}$, and $\mathrm{d}_{\mathrm{m}}<\mathrm{d}_{\mathrm{s}}$, implying a job ladder in which output increases faster with ability in the managerial job than in the subordinate job. In both periods, workers can choose any effort level in $\left[\mathrm{e}_{\mathrm{L}}, \mathrm{e}_{\mathrm{H}}\right]$, where $\mathrm{e}_{\mathrm{L}}=0$ is sometimes assumed. Worker i's cost of exerting effort in period $\mathrm{t}$ is $\alpha \mathrm{C}\left(\mathrm{e}_{\mathrm{it}}\right)$, where $\alpha>0$ and $\mathrm{C}(\mathrm{e})$ is defined as in the preceding section. Higher values of $\alpha$ lower the sensitivity of effort choices to incentives and frequently imply reduced effort.

The firm privately observes its workers' outputs each period, whereas second-period job assignments are publicly observed. After observing worker i's first-period output, $y_{i 1}$, the worker's employer forms an updated belief, $\eta^{\mathrm{e}}\left(\mathrm{y}_{\mathrm{i} 1}\right)$ at the start of period 2 concerning the worker's effective ability. The timing is as follows. At the start of the first period all firms make wage offers to each worker, and each worker chooses an employer. Then workers choose firstperiod effort, the value of $u$ is realized, and the worker's output is observed by his employer. At the start of the second period, the firm gives the worker a job assignment that is publicly observed. Each firm then makes the worker a wage offer, and the worker's original employer then makes the worker a counteroffer. Each worker then chooses an employer, switching firms only if offered a strictly higher wage. Then the worker chooses an effort level, the value of $u$ is realized, and the worker's employer privately observes the worker's output.

Since the model has two periods, the worker's second-period effort choice is zero as a result of the last-period problem. But in the first period, it may be in the interests of subordinates to exert effort levels beyond this minimum for the same reason as in the classic tournament model. That is, higher levels of first-period effort increase the subordinate's first-period output, which the employer privately observes and uses as the basis for a promotion decision. Thus, higher levels of first-period effort imply higher promotion probabilities - and the accompanying 
wage increases - in the next period. The following new result can now be shown: ${ }^{16}$

Proposition 1: In the performance standards model with endogenous worker effort, the opposing responses property (i.e. $\partial \mathrm{e}^{*} / \partial \theta<0$ and $\partial \mathrm{S}^{*} / \partial \theta>0$ ) fails to hold since $\partial \mathrm{S}^{*} / \partial \theta=0$.

The intuition for the result $\partial \mathrm{S}^{*} / \partial \theta=0$ follows from a winner's curse result that characterizes this model. ${ }^{17}$ Given that a worker's current employer is able to make a counteroffer to prevent the worker from separating to move to a competing firm, this suggests that any worker a competing firm can successfully raid in equilibrium must be of low quality. As a consequence, competing firms will only be willing to offer a firm's worker a wage equal to the lowest possible productivity (conditional on job assignment) that the worker would have in the same job in a competing firm. Given that competing firms are always bidding the lowest possible productivity conditional on job assignment, and given that this minimum productivity conditional on job assignment is not sensitive to changes in $\theta$, it follows that the equilibrium wage spread will also not be sensitive to changes in $\theta .^{18}$

To summarize, there are two important points of this section. First, in the performance standards model with endogenous effort choices, promotions are determined by absolute performance rather than relative performance. Second, these models do not exhibit the opposing responses property given that $\partial \mathrm{S}^{*} / \partial \theta$ is zero rather than positive. Finally, note that if the performance standards model does not incorporate endogenous worker effort then the first condition required by opposing responses, namely $\partial \mathrm{e}^{*} / \partial \theta<0$, obviously fails to hold given that $\partial \mathrm{e}^{*} / \partial \theta$ does not exist.

\section{Market-Based Tournaments With Endogenous Worker Effort}

If a managerial job slot constraint is imposed in the Ghosh and Waldman (2010) model described in the previous section, the model transforms from a performance standards model to a market-based tournament model. Waldman (2011) presents a discussion and a partial analysis of this extension, which changes the original model in three key ways, and I build on his discussion

\footnotetext{
${ }_{17}^{16}$ All proofs are in the Appendix.

${ }^{17}$ A winner's curse result is common in models of this type that incorporate counteroffers. See Milgrom and Oster (1987) and also Greenwald (1986), Lazear (1986), and DeVaro and Waldman (2011).

${ }^{18}$ In the market-based tournament model of the following section, I show that under some assumptions that eliminate the winner's curse property, the equilibrium wage spread is a function of $\theta$.
} 
here. First, there is now a single managerial position, so that relative performance determines promotions. The managerial job can either be staffed or left vacant. Second, the number of young workers hired in the first period is public information. To simplify the discussion, I will further assume throughout this section that there are two subordinates. Third, following Greenwald (1986), with a small probability the worker is assumed to separate in the second period for exogenous reasons unrelated to worker ability. Whether the separation occurs is publicly observed in the second period after the worker's original employer makes a wage counteroffer. This assumption eliminates or mitigates the winner's curse result that characterizes the model in the previous section that resulted in the equilibrium wage spread being insensitive to $\theta$. Now, competing firms will offer wages equal to the expected productivity of a worker in a given job assignment at a competing firm. In contrast, the winner's curse in its extreme form implies that competing firms only offer a worker a wage equal to the minimum productivity the worker would have in a given job assignment at a competing firm.

Using the previous section's notation, consider the case $\alpha<\infty$ so that first-period effort choices are potentially greater than zero. Given that introducing a managerial slot constraint significantly complicates the analysis, Waldman (2011) presents a partial analysis and informally discusses the main results, focusing on how the equilibrium wage spread varies with the number of subordinates competing for promotion in the second period. My focus is on how the equilibrium wage spread varies with $\theta$. As in Waldman's discussion, mine assumes there is a sufficient amount of firm-specific human capital to ensure that there is no turnover other than the aforementioned turnover for exogenous reasons and that the production function is such that the employer always wants to promote a subordinate in the second period (as opposed to leaving the managerial position unfilled). Under these assumptions, the worker with the highest period-1 output is promoted, and if there is a tie (which happens with probability zero) the firm randomly selects which worker to promote.

Call the subordinates $\mathrm{i}$ and $\mathrm{j}$. Under the preceding assumptions, competing firms offer a promoted worker a wage equal to the expected productivity of that worker in the managerial position at a competing firm, i.e. $\mathrm{W}_{\mathrm{m}}=\mathrm{d}_{\mathrm{m}}+\mathrm{c}_{\mathrm{m}} \mathrm{E}\left[\eta_{\mathrm{i} 2} \mid \mathrm{y}_{\mathrm{is} 1}>\mathrm{y}_{\mathrm{js} 1}\right]$, assuming without loss of generality that subordinate $\mathrm{i}$ is promoted. For the subordinate who is not promoted, competing 
firms will bid a wage equal to the expected productivity of that worker in the subordinate position at a competing firm, i.e. $W_{s}=d_{s}+c_{s} E\left[\eta_{j 2} \mid y_{i s 1}>y_{j s 1}\right]$, assuming without loss of generality that subordinate $\mathrm{j}$ is not promoted. The fact that workers cannot observe innate abilities (their own or their competitor's) implies a symmetric equilibrium in which the workers make identical first-period effort choices. The following new result can now be shown:

Proposition 2: In the market-based tournament model with endogenous worker effort, the opposing responses property (i.e. $\partial \mathrm{e}^{*} / \partial \theta<0$ and $\partial \mathrm{S}^{*} / \partial \theta>0$ ) fails to hold, given that $\partial \mathrm{e}^{*} / \partial \theta<0$ and $\partial \mathrm{S}^{*} / \partial \theta<0$.

The logic for $\partial \mathrm{e}^{*} / \partial \theta<0$ is similar to that in the classic tournament model. That is, holding the spread constant, increases in the variance induce decreases in subordinates' firstperiod effort, because the amount by which incremental effort increases the subordinate's probability of winning diminishes as random determinants of performance (and therefore promotion) become more important. Note that $\partial \mathrm{S}^{*} / \partial \theta$ differs in sign between the classic and market-based tournaments. The logic for $\partial \mathrm{S}^{*} / \partial \theta<0$ in the market-based model is as follows. When the variance increases, the quality of a firm's information regarding the ability of its subordinates deteriorates, implying more frequent mistakes in second-period job assignments. These mistakes imply that, in the eyes of competing employers, the expected ability of promoted workers decreases, and the expected ability of workers who are not promoted increases. If $\theta$ approaches 0 , then $u_{i 1}$ and $u_{j 1}$ disappear from the model, and $y_{i s 1}-y_{j s 1}=c_{s}\left(\eta_{i 1}-\eta_{j 1}\right)$, so that the firm observes the worker's ability and never makes mistakes in promotions decisions, i.e. the higher-ability subordinate gets the promotion. Thus, as shown in the appendix, expected effective ability of promoted workers in the eyes of competing employers is $\mathrm{E}\left(\eta_{\mathrm{i} 2} \mid \mathrm{i}\right.$ is promoted, $\left.\theta \rightarrow 0\right)=\mathrm{k}\left[\left(2 \rho-\rho^{2}\right) \mathrm{a}_{\mathrm{H}}+(1-\rho)^{2} \mathrm{a}_{\mathrm{L}}\right]$. In contrast, when $\theta \rightarrow \infty$ so that the firm's information about worker ability effectively disappears, then the firm often makes mistaken promotion decisions, and each worker's probability of promotion approaches 0.5 . In this case the expected effective ability of promoted workers in the eyes of competing employers is $\mathrm{E}\left(\eta_{\mathrm{i} 2} \mid \mathrm{i}\right.$ is promoted, $\left.\theta \rightarrow \infty\right)=\mathrm{k}\left[\rho \mathrm{a}_{\mathrm{H}}+(1-\rho) \mathrm{a}_{\mathrm{L}}\right]<\mathrm{E}\left(\eta_{\mathrm{i} 2} \mid \mathrm{i}\right.$ is promoted, $\left.\theta \rightarrow 0\right)$. Analogous expressions could be given for workers who are not promoted, such that in the eyes of competing employers $E\left(\eta_{\mathrm{i} 2} \mid \mathrm{i}\right.$ is not promoted, $\left.\theta \rightarrow 0\right)<E\left(\eta_{\mathrm{i} 2} \mid \mathrm{i}\right.$ is not promoted, $\left.\theta \rightarrow \infty\right)$. Since promoted 
workers and those who are not promoted are less differentiated in the eyes of competing employers when the variance is high (due to mistaken job assignments), the wages that competing firms offer to these two types of workers are also less differentiated.

Comparing this extension to the model in the previous section helps to clarify the intuition for the result that the equilibrium wage spread in the previous section is insensitive to $\theta$. In the previous section, because of the winner's curse, competing firms assume the worst about workers who separate from their initial employers, because their initial employers choose not to make counteroffers sufficient to keep them. In the present section, given the assumptions of exogenous turnover unrelated to ability and enough firm-specific human capital so that there is no other turnover, the winner's curse disappears, so competing employers are willing to bid a wage equal to a worker's expected productivity conditional on job assignment. As shown above, such expectations conditional on job assignments are sensitive to $\theta$ given that competing firms interpret $\theta$ as an indicator of how frequently the initial firm will make mistakes in its job assignments and will adjust their expectations about ability accordingly. Such adjustments in expectations by competing firms do not occur if, given a winner's curse, they are always bidding the minimum productivity conditional on job assignment.

To summarize, there are two important points of this section regarding market-based tournaments with endogenous effort. First, promotions are determined by relative performance. Second, the model does not exhibit the property of opposing responses, because $\partial \mathrm{S}^{*} / \partial \theta<0$ as opposed to $\partial \mathrm{S}^{*} / \partial \theta>0$. Although this result is derived under a very specific model specification, the basic intuition underlying the result seems general so the result should be robust to alternative specifications. Thus, the classic and market-based models are sharply distinguished by the effect of $\theta$ on the wage spread. When $\theta$ increases, first-period equilibrium effort choices decrease for two reasons. The first effect depresses equilibrium effort because incremental effort increases the probability of victory by a smaller amount, and the second effect depresses effort because the equilibrium wage spread, or tournament prize, shrinks. The fact that in classic tournaments workers and the firm adjust their choice variables in opposite directions in response to changes in $\theta$, whereas in market-based tournaments these adjustments are made in the same direction, is a testable implication that sharply distinguishes these two models. 


\section{Performance Standards With Endogenous Human Capital Investment}

In this section I return to the performance standards model, though in contrast to section 3 in which promotions created incentives for worker effort, in the present section promotions create incentives for worker investments in firm-specific human capital. ${ }^{19} \mathrm{I}$ focus the discussion on the well-known model of Prendergast (1993). In a one-period model, consider a two-level, flexible-slot job hierarchy with subordinate and managerial jobs, and a risk-neutral worker with reservation utility r. Given that job slots are flexible, promotions are determined by absolute performance. At a fixed cost, c, subordinates can invest in firm-specific human capital ( $h=1)$, or not $(\mathrm{h}=0)$. The advantage of investing is that firm-specific human capital enhances productivity, thereby raising the likelihood that a worker's performance will meet or exceed the standard for promotion. The firm assigns the worker to one of the jobs after observing the worker's output. Once assigned, a worker cannot quit or be fired.

Let $\mathrm{u}$ denote the stochastic component of performance. Prendergast interprets $\mathrm{u}$ as worker ability or match quality, but in a one-period model it can be thought of as in the models in preceding sections. That is, to workers and the firm u represents one-time random shocks to worker performance that are unobserved when decisions are made. Production functions for managers and subordinates are commonly known and are as follows: $\mathrm{y}_{\mathrm{m}}(\mathrm{h}, \mathrm{u})$ and $\mathrm{y}_{\mathrm{s}}(\mathrm{h}, \mathrm{u})$, where both functions are non-decreasing in both arguments. Prendergast assumes u is uniformly distributed on $[0,1]$ and therefore does not consider the effect of changes in the variance of u, i.e. $\theta$. Given that my focus is on the effect of changes in this variance, I extend the model by instead assuming that $\mathrm{u}$ is uniformly distributed on $[\mathrm{m}-\mathrm{a}, \mathrm{m}+\mathrm{a}]$, where $0<\mathrm{a} \leq \mathrm{m}$, so that $\theta \equiv \operatorname{Var}(\mathrm{u})=\mathrm{a}^{2} / 3$. The two key assumptions on the production function are as follows:

(i) $\partial \mathrm{y}_{\mathrm{m}}(\mathrm{h}, \mathrm{u}) / \partial \mathrm{u} \geq \partial \mathrm{y}_{\mathrm{s}}(\mathrm{h}, \mathrm{u}) / \partial \mathrm{u} \geq 0$ for all $\mathrm{h}$;

(ii) $\mathrm{y}_{\mathrm{m}}(1, \mathrm{u})-\mathrm{y}_{\mathrm{m}}(0, \mathrm{u})>\mathrm{y}_{\mathrm{s}}(1, \mathrm{u})-\mathrm{y}_{\mathrm{s}}(0, \mathrm{u}) \forall \mathrm{u} \in[\mathrm{m}-\mathrm{a}, \mathrm{m}+\mathrm{a}]$.

As in classic tournaments, the firm pre-commits to wages $\mathrm{W}_{\mathrm{m}}$ and $\mathrm{W}_{\mathrm{s}}$ to induce incentives. These wages are attached to jobs and cannot be conditioned on worker output or on

\footnotetext{
${ }^{19}$ The importance of human capital investments in determining promotions was stressed earlier in Carmichael (1983) and more recently in Zábojník and Bernhardt (2001) and Zábojník (2011). Empirical support for the idea was found in a study of promotions in a major American fast-food retailer (Campbell 2008).
} 
the worker's choice of $h$. After observing $W_{m}$ and $W_{s}$, the worker chooses either $h=1$ or $h=0$ to maximize utility of $U=W-c h$, where $W$ is the wage paid. The firm then observes the worker's output in each job prior to making the job assignment. The firm is risk-neutral and maximizes expected profit - i.e. worker output minus the wage - subject to four constraints: worker incentive compatibility, worker individual rationality, firm incentive compatibility when $\mathrm{h}=1$ (this constraint defines $\mathrm{u}^{*}$, the performance standard for promotion for the case when $\mathrm{h}^{*}=1$ ) and firm incentive compatibility when $\mathrm{h}=0$ (this constraint defines $\mathrm{u}^{\prime}$, the performance standard for promotion for the case when $\mathrm{h}^{*}=0$ ). It can be shown that $\mathrm{u}^{*} \leq \mathrm{u}^{\prime}$. Given that the worker's choice variable is binary rather than continuous, one of the two conditions for opposing responses requires slight modification. Opposing responses in this context requires that as $\theta$ increases, the worker is less inclined to choose $h=1$ and more inclined to choose $h=0$, holding the wage spread constant. It also requires that $\partial \mathrm{S}^{*} / \partial \theta>0$. The following new result can now be stated:

Proposition 3: In the performance standards model with endogenous human capital investment the opposing responses property does not hold in general. As $\theta$ increases, the worker is less inclined to choose $\mathrm{h}=1$ and more inclined to choose $\mathrm{h}=0$, holding the wage spread constant. However, the second condition required for opposing responses may or may not hold, given that the sign of $\partial \mathrm{S}^{*} / \partial \theta$ is ambiguous.

The fact that $\partial \mathrm{S}^{*} / \partial \theta$ is ambiguous in sign can be understood as follows. As discussed in Prendergast (1993), the worker's incentive compatibility constraint binds in equilibrium. In the present extension of the model, that implies $\left(u^{\prime}-u^{*}\right) S^{*}=2 c(3 \theta)^{0.5}$. An increase in $\theta$ would require an increase in the left-hand side of the preceding equation, which is the product of the wage spread and the difference in promotion standards when the worker does not invest versus when the worker invests. Differentiating the left-hand side with respect to $S^{*}$ yields $\left[\partial\left(u^{\prime}-\right.\right.$ $\left.\left.\mathrm{u}^{*}\right) / \partial \mathrm{S}^{*}\right] \mathrm{S}^{*}+\left(\mathrm{u}^{\prime}-\mathrm{u}^{*}\right)$. As noted earlier, $\mathrm{u}^{\prime}-\mathrm{u}^{*}$ is non-negative, and it can also be shown that $\mathrm{u}^{\prime}$ and $\mathrm{u}^{*}$ are both non-decreasing in the wage spread. However, $\partial\left(\mathrm{u}^{\prime}-\mathrm{u}^{*}\right) / \partial \mathrm{S}^{*}$ cannot be signed without further structure imposed on the production functions. If that partial derivative is positive (so that the promotion standards for the $\mathrm{h}=0$ and $\mathrm{h}=1$ cases diverge as the wage spread increases) then increases in risk imply increases in the spread, as required for the opposing responses property to hold. However, if the partial derivative is negative so that the promotion 
standards for the $\mathrm{h}=0$ and $\mathrm{h}=1$ cases become more similar as the wage spread increases, then an increase in risk might decrease the equilibrium wage spread.

To summarize, there are two important points of this section. First, in the performance standards model with worker investments in firm-specific human capital, promotions are determined by absolute performance. Second, this model does not offer a clear prediction concerning the opposing responses property, which may or may not hold depending on the form of the production functions. Although the relative payoff to the worker of choosing $h=1$ over $h$ $=0$ is decreasing in $\theta, \partial \mathrm{S}^{*} / \partial \theta$ is ambiguous in sign.

\section{Market-Based Tournaments With Endogenous Human Capital Investments}

I now return to internal promotion competitions characterized by fixed managerial job slots, so that promotions are determined by relative performance. In this section the worker's choice variable is a human capital investment. As in the market-based tournament model of section 4 that relies on the wage-setting mechanism introduced in Waldman (1984a), wage spreads emerge ex post when competing firms bid in a spot market for the services of a recently promoted worker, based on the inference that a promotion signals the worker is of high ability. This in turn requires the worker's employer to raise the wage to prevent the worker from being raided by competitors. Combining these features, Zábojník and Bernhardt (2001) produced the first formal analysis of market-based tournaments. I focus this section on that setup and the closely related analysis of Zábojník (2011). ${ }^{20}$

Consider a two-level job hierarchy with one managerial position and two subordinate positions so that promotions are determined by relative performance. Firms and workers are riskneutral with common discount factor $\delta<1$. There are two periods. In period 1, worker i chooses a level of human capital investment, $\mathrm{h}_{\mathrm{i}}$, to maximize expected utility. The investment is made at a cost $\mathrm{C}\left(\mathrm{h}_{\mathrm{i}}\right)$, where $\mathrm{C}$ is a standard cost function as defined in section $2 .{ }^{21}$ Subordinate i's total

\footnotetext{
20 Zábojník (2011) notes that a reason for focusing on human capital rather than effort as the choice variable in market-based tournament models is that the conflict between the assignment and incentives functions of promotions (see the first paragraph of the introduction) is less pronounced in the case of human capital investments than in the case of effort. This is because promoting the highest-skilled worker fits well with both functions of promotions.

${ }^{21}$ In contrast to the model of Prendergast (1993) discussed in section 5 in which human capital investments were binary and firm-specific, here they are continuous and a blend of general and firm-specific. Some of the human
} 
human capital is given by $h_{i}{ }^{\prime}=h_{i}+u_{i}$, where $u_{i}$ is a stochastic component distributed uniformly on $[\alpha, \beta], \alpha>0$, and $\theta \equiv \operatorname{Var}\left(u_{i}\right)=(\beta-\alpha)^{2} / 12$. Subordinate $j$ 's problem is symmetric, and $u_{i}$ and $u_{j}$ are independent and drawn from the same distribution. The shocks $u_{i}$ and $u_{j}$ reflect human capital developed passively through learning by doing. Firms are characterized by productivity parameters, $\mathrm{V}$, which can be thought of as the price at which output is sold. The parameter $\mathrm{V}$ can assume either a high value, $\mathrm{V}_{\mathrm{H}}$, or a low value, $\mathrm{V}_{\mathrm{L}}$, where $0<\mathrm{V}_{\mathrm{L}}<\mathrm{V}_{\mathrm{H}}$. A subordinate who has chosen human capital $\mathrm{h}$ and remains with the original employer (with productivity parameter $\mathrm{V}$ ) in the second period contributes V $\gamma \mathrm{h}$ to the firm's revenue, where $\gamma>1$. If instead the subordinate switches in the second period to an employer with productivity parameter $\mathrm{V}^{\prime}$, the worker will contribute V'h to the new employer's revenues, i.e. $\gamma-1$ captures the firm-specific part of the worker's human capital that is lost when switching employers.

At the end of the first-period, the firm privately observes each subordinate's h' and promotes the one with the higher value to the managerial position in the second period, retaining the other worker as a subordinate. ${ }^{22}$ As in Waldman (1984a), competing firms do not observe each worker's h' but do observe second-period job assignments. Based on that observation, competing firms then formulate expectations about each worker's level of accumulated human capital, h', that directly affects the worker's second-period productivity. Second-period wages for the manager and subordinate, $\mathrm{W}_{\mathrm{m}}$ and $\mathrm{W}_{\mathrm{s}}$, are determined by spot market contracting at the start of the second period. The worker's current employer and competing firms simultaneously make wage bids, and workers accept the highest offer, switching firms only for a strictly higher wage. Under some parametric restrictions, there is no turnover in equilibrium because the worker's employer increases the promoted worker's wage sufficiently to prevent a separation, thereby generating a wage difference across hierarchical levels. Thus, in this market-based tournament model as in that of section 4 , incentives are created by the anticipation of workers that wage spreads will emerge following a promotion, whereas in a classic tournament incentives arise from the firm's pre-commitment to a wage spread before the workers invest.

capital must be general so that competing firms value it and will be inclined to bid more for workers suspected of having acquired it, which is the key mechanism generating wage dispersion across hierarchical levels.

${ }^{22}$ Other papers considering how asymmetric information in labor markets affects human capital investments are Waldman (1990), Chang and Wang (1996), and Acemoglu and Pischke (1998). 
Two important differences between this market-based tournament model and the one from section 4 in which the worker's first-period choice variable is effort are worth highlighting. First, when the worker's first-period choice variable is a human capital investment, it directly translates into increased second-period productivity. In contrast, in the market-based model of section 4, the subordinate's first-period effort choice does not directly translate into higher second-period productivity. This matters given that second-period wages are determined by the beliefs of competing firms concerning the workers' second-period productivities. Second, like the worker's first-period choice variable, the stochastic component of the worker's first-period human capital is also persistent in that high values of $u_{i}$ translate into high values of $h_{i}{ }^{\prime}$, which directly determine second-period productivity. The stochastic term is also strictly positive and thus always productivity-enhancing, consistent with its interpretation of "learning by doing". In contrast, in the market-based model of section 4, as in the Lazear and Rosen (1981) classic tournament model of section 2 , the $\mathrm{u}_{\mathrm{i}}$ is a one-time mean-zero "luck" term that affects the worker's first-period output (either positively or negatively) but does not persist. ${ }^{23}$

The difference in interpretations of $\mathrm{u}_{\mathrm{i}}$ between the two market-based models is potentially important given that the empirical test based on opposing responses that I describe in subsequent sections assumes that the interpretation of $\mathrm{u}_{\mathrm{i}}$ is similar across models being compared, so that the effects of changes in $\theta$ can be meaningfully compared across models. Given that the interpretation of $\mathrm{u}_{\mathrm{i}}$ in the market-based model of section 4 matches that of the classic tournament model of section 2 (i.e. both are mean-zero performance shocks that do not persist) whereas the interpretation of $u_{i}$ in the market-based model of this section is somewhat different (i.e. it is strictly positive and persistent), comparing the models of sections 2 and 4 might be more appropriate than comparing the models of sections 2 and 6 for the purpose of comparing classic and market-based tournaments.

Zábojník and Bernhardt (2001) show that in equilibrium a worker's second-period wage equals his expected productivity in a competing firm conditional on his job assignment with the

\footnotetext{
${ }^{23}$ Note that these distinctions between the two types of market-based models arise because both are two-period models. In contrast, these issues do not arise in the performance standards model of section 5 given that it has only one period so that neither the first-period choice variable nor the first-period shock can persist into a future period.
} 
first-period employer. The equilibrium wages are $\mathrm{W}_{\mathrm{m}}(\mathrm{V})=\mathrm{V}_{\mathrm{H}}\left(\mathrm{h}^{*}(\mathrm{~V})+\mathrm{E}\left[\mathrm{u}_{(2)}\right]\right)$ and $\mathrm{W}_{\mathrm{s}}(\mathrm{V})=$ $\mathrm{V}_{\mathrm{H}}\left(\mathrm{h}^{*}(\mathrm{~V})+\mathrm{E}\left[\mathrm{u}_{(1)}\right]\right)$, where $\mathrm{u}_{(\mathrm{k})}$ denotes the $\mathrm{k}^{\text {th }}$ order statistic of two draws from the distribution of $\mathrm{u}$, so the equilibrium wage spread is $\mathrm{S}^{*} \equiv \mathrm{W}_{\mathrm{m}}-\mathrm{W}_{\mathrm{s}}=\mathrm{V}_{\mathrm{H}}\left(\mathrm{E}\left[\mathrm{u}_{(2)}\right]-\mathrm{E}\left[\mathrm{u}_{(1)}\right]\right)$. In the symmetric pure strategy equilibrium, both workers choose the same optimal level of $\mathrm{h}$, denoted $\mathrm{h}^{*}$ and defined by the first-order condition: $\delta\left(\mathrm{W}_{\mathrm{s}}-\mathrm{W}_{\mathrm{m}}\right) \mathrm{q}(0)=\mathrm{C}^{\prime}\left(\mathrm{h}^{*}\right)$, where $\mathrm{q}(0) \equiv \int_{\alpha}^{\beta} f_{u}^{2}(u) d u$. This is exactly the first-order condition from the classic two-player tournament model of Lazear and Rosen (1981), as given in section 2, except that now the wage spread is determined ex post by labor market competition rather than being set strategically by the firm ex ante to induce effort.

As in the previous sections, the worker's choice variable is increasing in the wage spread, i.e. $\partial \mathrm{h}^{*} / \partial\left(\mathrm{W}_{\mathrm{m}}-\mathrm{W}_{\mathrm{s}}\right)>0$. This result says simply that wage spreads from promotion have incentive effects in that larger prizes motivate higher levels of investment (in either effort or human capital) on the part of subordinates. Now consider the responses of $\mathrm{h}^{*}$ and $\mathrm{S}^{*}$ to changes in $\theta$. Recall that in the classic tournament model, an increase in $\theta$ holding the spread constant implied a decrease in effort, i.e. $\partial \mathrm{e}^{*} / \partial \theta<0$. At the same time, the increase in $\theta$ implied an increase in the equilibrium wage spread, i.e. $\partial \mathrm{S}^{*} / \partial \theta>0$. Given that $\partial \mathrm{e}^{*} / \partial\left(\mathrm{W}_{\mathrm{m}}-\mathrm{W}_{\mathrm{s}}\right)>0$, this increase in the spread worked in the direction of increasing $\mathrm{e}^{*}$. In the classic model these two opposing effects on $\mathrm{e}^{*}$ of an increase in $\theta$ were exactly offsetting. Zábojník and Bernhardt (2001) showed that given that $u$ has the uniform distribution, the same result of exactly offsetting effects holds in the market-based model so that $\mathrm{h}^{*}$ remains unchanged in response to changes in $\theta .{ }^{24} \mathrm{In}$ the market-based tournament with endogenous human capital investments, an increase in risk has two effects. First, it decreases the marginal effect of human capital on the probability of promotion - i.e. decreases $\mathrm{q}(0)$ - just as in the classic model it decreases $\mathrm{g}(0)$, and this tends to decrease $h$. Second, it increases the spread, which tends to increase $h$. The reason why the spread is increasing in $\theta$ can be understood by recalling that the equilibrium spread is $\mathrm{V}_{\mathrm{H}}\left(\mathrm{E}\left[\mathrm{u}_{(2)}\right]-\right.$ $\left.\mathrm{E}\left[\mathrm{u}_{(1)}\right]\right)$ and noting that the difference in the expectations of the first two order statistics is increasing in the variance of the underlying random variable. Intuitively, if the variance of $u$ is

\footnotetext{
${ }^{24}$ Given the uniform distribution, the worker's first-order condition can be rewritten as $\mathrm{C}^{\prime}\left(\mathrm{h}^{*}\right)=\delta \mathrm{V} / 3$, in which $\theta$ does not appear.
} 
small, then the expected difference in productivities between the tournament winner and loser will be small in the symmetric equilibrium, which in turn justifies a small wage spread.

Although the market-based model exhibits the same property of offsetting effects of changes in $\theta$ on the worker's choice variable as the classic model, it does so under more restrictive distributional assumptions. In particular, whereas the model of section 2 imposed no strong distributional assumptions other than symmetry, Zábojník and Bernhardt (2001) assumed a uniform distribution on $[\alpha, \beta]$. In the following proposition I generalize the result.

Proposition 4: Assume that u has an arbitrary, continuous, symmetric distribution on support $[\alpha, \beta]$. Then the effects of changes in $\theta$ on $\mathrm{q}(0)$ and $\mathrm{W}_{\mathrm{m}}-\mathrm{W}_{\mathrm{s}}$ are exactly offsetting, so ${ }^{*}$ does not depend on $\theta$.

The importance of Proposition 4 can be understood as follows. The main result is that the model of this section, like the classic tournament model of section 2, exhibits the property of opposing responses, which gives rise to an empirical test to be explained in subsequent sections. As noted at the end of section 2, in the classic model this prediction relies on weak distributional assumptions. Zábojník and Bernhardt (2001) showed that the same result holds in the marketbased model if $\mathrm{u}$ is uniform on $[\alpha, \beta]$ and $\alpha$ is sufficiently positive, but absent Proposition 4 it would be unclear how robust this prediction is and whether it is an artifact of the uniform distribution (in which case it would be misleading to argue that the model exhibits the same property as classic tournaments). By weakening the distributional assumptions, proposition 4 strengthens the conclusion that both models exhibit the opposing responses property. ${ }^{25}$

I now summarize the key points of this section. First, in the market-based tournament model with endogenous human capital investments, promotions are determined by relative performance. Second, in contrast to the market-based tournament model of section 4 , the present one exhibits opposing responses, i.e. $\partial \mathrm{h}^{*} / \partial \theta<0$ and $\partial \mathrm{S}^{*} / \partial \theta>0$. One important implication of

\footnotetext{
${ }^{25}$ The results still rely on a bounded support, in contrast to the classic tournament model of section 2 or the marketbased tournament model of section 4. Zábojník and Bernhardt (2001) assume that $\alpha$ is strictly positive and sufficiently high so that there is no turnover in equilibrium, i.e. $\alpha \geq \beta \mathrm{V}_{\mathrm{H}} /\left(\gamma \mathrm{V}_{\mathrm{L}}\right)$. Zábojník (2011) imposes a less stringent lower bound on $\alpha$ which allows it to be negative, i.e. $\alpha \geq-\mathrm{C}^{-1}\left(\delta \mathrm{V}_{\mathrm{H}} \mathrm{q}(0)\left(\mathrm{E}\left[\mathrm{u}_{(2)}\right]-\mathrm{E}\left[\mathrm{u}_{(1)}\right]\right)\right)$. The purpose of the latter assumption is to ensure that the worker's human capital is always non-negative.
} 
this is that the two different approaches to modeling market-based tournaments (i.e. worker effort choices versus worker human capital investments) are sharply distinguished by the property of opposing responses. Another important result is that the relative-versus-absolute performance and opposing responses predictions are insufficient for distinguishing market-based tournaments with human capital investments from classic tournaments with effort choices. In section 9 I propose a new way in which the two models might be distinguished in future work.

\section{An Econometric Framework For Distinguishing Among Alternative Promotion Models}

In the class of models for which promotions create incentives for worker effort, the two tests based on opposing responses and relative-versus-absolute performance are sufficient to empirically distinguish among the three core promotion models in Figure 1 (i.e. classic tournaments, market-based tournaments, and performance standards). If we broaden the focus to include models in which workers choose human capital investments instead of effort, two additional results emerge. First, the two tests are sufficient to distinguish sharply between the two types of market-based tournaments (i.e. those based on effort choices and those based on human capital investments). Second, the two tests cannot distinguish between classic tournaments with effort choices and market-based tournaments with human capital investment choices. The two tests can be conducted either separately (as in the next two subsections) or in a single estimation framework as in subsection 7.3.

\subsection{Testing Whether Promotions Are Based on Relative or Absolute Performance}

An empirical test of whether promotions are determined by relative or absolute performance requires data on worker performance, the performance of a worker's competitors, and promotion outcomes. A single-equation probit model is sufficient to test this prediction, where the dependent variable equals one if worker $i$ was promoted and 0 if worker $i$ was not promoted. The key independent variables are $P_{i}$, the performance of worker $i$ in the prepromotion job, and $\mathrm{P}_{0 \mathrm{i}}$, the performance of worker i's competitors in that same job. If relative performance determines promotions, then the coefficient of $\mathrm{P}_{\mathrm{i}}$ in the probit model should be positive, and that of $\mathrm{P}_{0 \mathrm{i}}$ should be negative, whereas if absolute performance determines promotions, then the coefficient of $\mathrm{P}_{\mathrm{i}}$ should be positive and that of $\mathrm{P}_{0 \mathrm{i}}$ should be zero. I discuss 
empirical evidence from such a test in section 8, which allows the two main branches of Figure 1 to be distinguished empirically.

\subsection{Testing the Opposing Responses Property}

Given the data that are typically available, testing the opposing responses prediction requires a simultaneous-equations estimation framework so that predictions regarding the unobserved data (i.e. $\theta$ ) can be translated into a prediction about the sign of the cross-equation error correlation. I start by constructing an empirical model based on classic tournaments, given that this model motivates the largest share of the empirical literature on promotions, indicating throughout the discussion what parametric predictions would be implied by classic tournaments and what predictions would be implied by each of the alternative models. Recall that the worker's first-order condition in a classic tournament is $g(0) S-C^{\prime}\left(e^{*}\right)=0$ and that $g(0)$ is inversely related to $\theta$. A linear approximation of this condition could be used as the basis for an estimating equation in which $\mathrm{e}^{*}$ is the dependent variable. But since data on effort are typically unavailable, whereas performance data are sometimes available, this linear approximation can be substituted into the production function $\mathrm{P}=\mathrm{e}^{*}+\mathrm{u}$, yielding the following regression equation, where the equilibrium wage spread is $\mathrm{S}^{*} \equiv \mathrm{W}_{\mathrm{m}}-\mathrm{W}_{\mathrm{s}}$ :

$\mathrm{P}_{\mathrm{i}}=\alpha_{0}+\alpha_{1} \mathrm{~S}_{\mathrm{i}}^{*}+\tau \theta_{\mathrm{i}}+\varepsilon_{1 \mathrm{i}}{ }^{*}$

The opposing responses property requires $\partial \mathrm{e}^{*} / \partial \theta<0$, which implies $\tau<0$ in the preceding regression. Thus, given data on $\mathrm{P}_{\mathrm{i}}, \mathrm{S}_{\mathrm{i}}{ }^{*}$, and $\theta_{\mathrm{i}}$ across tournaments, a researcher could estimate the preceding regression and then test the "first half" of the opposing responses property (i.e. the part pertaining to worker behavior) by testing the null hypothesis $\tau=0$ against the alternative $\tau<0$, using a one-tailed test. Rejecting the null would favor any of the internal promotion competitions or the performance standards model with endogenous worker choices, whereas failing to reject it would favor the other performance standards model with no worker choice.

There are two problems with this test. First, data on $\theta_{\mathrm{i}}$ spanning multiple tournaments would not normally be available given that $\theta_{\mathrm{i}}$ is inherently difficult to measure, so $\theta_{\mathrm{i}}$ would be subsumed in the regression disturbance term, yielding the model:

$\mathrm{P}_{\mathrm{i}}=\alpha_{0}+\alpha_{1} \mathrm{~S}_{\mathrm{i}}{ }^{*}+\varepsilon_{1 \mathrm{i}} \quad$ where $\varepsilon_{1 \mathrm{i}}=\tau \theta_{\mathrm{i}}+\varepsilon_{1 \mathrm{i}}{ }^{*}$.

This regression is unhelpful for testing the "first half" of opposing responses, since $\tau$ cannot be 
estimated. Second, $\mathrm{S}^{*}$ appears on the right-hand side of the regression even though it is endogenous in the theoretical model. This is a problem because factors unobserved to the econometrician are likely to affect both $\mathrm{S}^{*}$ and $\mathrm{P}$, biasing all of estimated coefficients in the model. This is a problem in both of the preceding regressions, but it is a particular problem in the more practically relevant second regression, because $\theta$ appears in $\varepsilon_{1}$ and is correlated with $S^{*}$ by the first-order conditions of the classic model.

With the exception of DeVaro (2006a,b) the previous literature has not addressed this second problem and has estimated the preceding regression treating $\mathrm{S}^{*}$ as exogenous. Although alone this regression is unhelpful for testing opposing responses, it has been used in previous work to test whether tournaments have incentive effects, i.e. $\alpha_{1}>0$ as implied by $\partial \mathrm{e}^{*} / \mathrm{S}>0$. The typical finding in such studies is $\alpha_{1}>0$ which is interpreted as evidence that tournaments have incentive effects. Even setting aside the endogeneity problem, the prediction $\alpha_{1}>0$ is unhelpful for distinguishing among the models of Figure 1, because it is common to all of them. If promotions are associated with wage increases, and if workers can take performance-enhancing actions that increase the probability of promotion, then incentives are automatically implied regardless of a) whether managerial job slots are fixed or flexible, b) the mechanism generating wage spreads, and c) the workers' choice variables.

Whereas empirical tests of $\alpha_{1}>0$ are based on worker behavior, another body of previous empirical work on tournaments has focused instead on firm behavior. ${ }^{26}$ Recall that in classic tournaments the optimal wage spread is $\mathrm{W}_{\mathrm{m}}-\mathrm{W}_{\mathrm{s}}=1 / \mathrm{g}(0)$, where $\mathrm{g}(0)$ is inversely related to $\theta$. A linear approximation of this condition yields the following regression model:

$S_{i}^{*}=\beta_{0}+\varphi \theta_{i}+\varepsilon_{2 i}^{*}$

The classic model predicts $\varphi>0$, given that the first-order conditions imply $\partial \mathrm{S}^{*} / \partial \theta>0$. Thus, given data on $\mathrm{S}_{\mathrm{i}}{ }^{*}$ and $\theta_{\mathrm{i}}$ across tournaments, a researcher could test the "second half" of the opposing property (i.e. the part related to firm behavior) by estimating the preceding regression and testing the null hypothesis $\varphi=0$ against the alternative that $\varphi \neq 0$, using a two-tailed test. Failure to reject the null would favor the performance standards models from section 3 .

\footnotetext{
${ }^{26}$ Representative studies include O’Reilly, Main, and Crystal (1988), Lambert, Larcker, and Weigelt (1993), Main, O’Reilly, and Wade (1993), Eriksson (1999), and Bognanno (2001).
} 
Rejecting the null and finding $\varphi>0$ would favor classic tournaments or either of the models with endogenous human capital investments, whereas rejecting the null and finding $\varphi<0$ would favor market-based tournaments with endogenous effort or perhaps the performance standards model with human capital. Market-based tournaments with endogenous effort would thus be sharply distinguished both from classic tournaments and from market-based tournaments with endogenous human capital investments. However, since data on $\theta_{\mathrm{i}}$ are typically unavailable, the term $\varphi \theta_{\mathrm{i}}$ is subsumed in the regression error, yielding:

$\mathrm{S}_{\mathrm{i}}{ }^{*}=\beta_{0}+\varepsilon_{2 \mathrm{i}}$ where $\varepsilon_{2 \mathrm{i}}=\varphi \theta_{\mathrm{i}}+\varepsilon_{2 \mathrm{i}}{ }^{* 27}$

This regression alone is unhelpful for testing opposing responses, since $\varphi$ cannot be estimated.

The bottom line is that when $\theta_{\mathrm{i}}$ is unobserved to the econometrician - which is the practically relevant case - neither the performance regression estimated alone nor the spread equation estimated alone allows the opposing responses property to be empirically tested. I now show that if the two equations are estimated jointly then under some identifying assumptions the parameter $\sigma_{12} \equiv \operatorname{cov}\left(\varepsilon_{1 \mathrm{i}}, \varepsilon_{2 \mathrm{i}}\right)$ can be estimated, and the opposing responses property combined with the fact that $\theta_{\mathrm{i}}$ is an important common component of $\varepsilon_{1 \mathrm{i}}$ and $\varepsilon_{2 \mathrm{i}}$ allows a prediction on the sign of $\sigma_{12}$. Let $\left(\varepsilon_{1 \mathrm{i}}, \varepsilon_{2 \mathrm{i}}\right)$ follow the bivariate normal distribution with mean vector $\mathbf{0}$ and covariance matrix $\Sigma$. Note that $\sigma_{12}=\tau \varphi \operatorname{Var}\left(\theta_{\mathrm{i}}\right)+\operatorname{cov}\left(\varepsilon_{1 \mathrm{i}}{ }^{*}, \varepsilon_{2 \mathrm{i}}{ }^{*}\right)$, where $\operatorname{Var}\left(\theta_{\mathrm{i}}\right)$ is the variance (across tournaments in the sample) of the variance (for a particular tournament in the sample) of $\mathrm{u}$. The parameter $\theta$ plays a critical role in the theoretical model (and in the other theoretical models in Figure 1), so from a theoretical standpoint $\theta_{\mathrm{i}}$ can be expected to be the principal common component of both $\varepsilon_{1 \mathrm{i}}$ and $\varepsilon_{2 \mathrm{i}}$ given that the other important components of the tournament model (i.e. the wage spread and worker performance) are already included in the model as observed data. When the simultaneous equations model is properly specified with a complete set of controls, then $\operatorname{cov}\left(\varepsilon_{1 \mathrm{i}}{ }^{*}, \varepsilon_{2 \mathrm{i}}{ }^{*}\right) \cong 0$. Given $\operatorname{cov}\left(\varepsilon_{1 \mathrm{i}}{ }^{*}, \varepsilon_{2 \mathrm{i}}{ }^{*}\right) \cong 0, \sigma_{12} \cong \tau \varphi \operatorname{Var}\left(\theta_{\mathrm{i}}\right)$, so the predicted sign of $\sigma_{12}$ hinges on the signs of $\tau$ and $\varphi$.

The two requirements of opposing responses, i.e. $\tau<0$ and $\varphi>0$, $\operatorname{imply} \tau \varphi \operatorname{Var}\left(\theta_{\mathrm{i}}\right)<0$ and thus $\sigma_{12}<0$. In contrast, in the performance standards model with worker effort or with no

\footnotetext{
${ }^{27}$ Note that linearity of $\varepsilon_{1 \mathrm{i}}$ and $\varepsilon_{2 \mathrm{i}}$ in $\theta_{\mathrm{i}}$ is not essential.
} 
worker choice, $\varphi=0$ implies $\sigma_{12}=0$. And in the market-based tournament model with endogenous effort, $\tau<0$ and $\varphi<0$ imply $\tau \varphi \operatorname{Var}\left(\theta_{\mathrm{i}}\right)>0$, and thus $\sigma_{12}>0$, sharply distinguishing this model from either of the other tournament models. Thus, even in the absence of data on $\theta$, the econometrician can test the opposing responses property by estimating the $\mathrm{P}$ and $\mathrm{S}$ * equations jointly and then testing the null hypothesis that $\sigma_{12}=0$ against the alternative $\sigma_{12} \neq 0$, using a two-tailed test. Rejecting the null in the direction of $\sigma_{12}<0$ favors classic tournaments or market-based tournaments with human capital investments, rejecting the null in the direction of $\sigma_{12}>0$ favors market-based tournaments with worker effort, and failing to reject the null favors the performance standards models. As shown in section 5, the performance standard model with human capital investments has no consistent prediction on the sign of $\sigma_{12}$.

There are two points to make regarding the controls for worker and firm characteristics that would in practice be included in the regressions for $\mathrm{P}$ and $\mathrm{S}^{*}$. First, given that the models are linear, identification of the $\mathrm{P}$ equation requires that at least one exogenous variable appearing in the $\mathrm{S}^{*}$ equation be excluded from the $\mathrm{P}$ equation. Second, the ideal specification of the econometric model is one that minimizes unobserved heterogeneity (across tournaments in the sample) in dimensions other than risk (by including a sufficient set of controls) but maximizes heterogeneity across tournaments in the degree of risk. This is because identification of $\sigma_{12}$ is based on cross-tournament variation in $\theta_{\mathrm{i}}$ that is unobserved by the econometrician but observed by economic agents. Samples that mix tournaments that are expected to differ widely in their levels of risk are ideal from the standpoint of testing the opposing responses prediction, since then $\sigma_{12}$ will be large in magnitude under the alternative hypothesis, increasing the likelihood that the null of $\sigma_{12}=0$ will be rejected when it is false. If the econometrician selects samples of tournaments that are too homogeneous with respect to risk, if the model includes insufficient controls, or if controls are included that proxy for risk, the test will be biased towards a finding of $\sigma_{12}=0$. However, in the case of controls that proxy for risk being included in the model, the researcher's attention should shift from a statistical test on $\sigma_{12}$ to statistical tests on $\tau$ and $\varphi$ as discussed earlier in the subsection, since in such cases risk is (at least partially) observable. 


\subsection{Nesting Internal Promotion Competitions and Performance Standards Models}

The relative-versus-absolute performance test can be based either on data spanning multiple tournaments or on data from a single firm/tournament. Testing the opposing responses property, however, requires data spanning multiple tournaments. In the following discussion I assume the availability of cross sectional data on one worker (and tournament) per firm, with i indexing both the worker and the firm, though the method could also be applied using panel data or cross sectional data with multiple workers per firm. Consider the following system:

$\mathrm{P}_{\mathrm{i}}=\alpha_{0}+\alpha_{1} \mathrm{~S}_{\mathrm{i}}^{*}+\mathbf{X}_{\mathrm{i}} \boldsymbol{\alpha}_{2}+\varepsilon_{1 \mathrm{i}}$

$\mathrm{S}_{\mathrm{i}}^{*}=\boldsymbol{\beta}_{0}+\mathbf{F}_{\mathrm{i}} \boldsymbol{\beta}_{1}+\mathbf{X}_{\mathrm{i}} \boldsymbol{\beta}_{2}+\varepsilon_{2 \mathrm{i}}$

$\mathrm{T}_{\mathrm{i}}^{*}=\gamma_{0}+\mathbf{F}_{\mathrm{i}} \gamma_{1}+\mathbf{X}_{\mathrm{i}} \gamma_{2}+\gamma_{3} \mathrm{P}_{0 \mathrm{i}}+\varepsilon_{3 \mathrm{i}}$

Promote $_{\mathrm{i}}=1$ if $\mathrm{P}_{\mathrm{i}}-\mathrm{T}_{\mathrm{i}}^{*} \geq 0$

$=0$ otherwise

where $\mathrm{P}_{\mathrm{i}}$ denotes worker i's performance in the lower-level job, $\mathrm{S}_{\mathrm{i}}^{*}$ denotes the wage spread between worker i's (low) job level and the next level up, $\mathrm{T}_{\mathrm{i}}{ }^{*}$ denotes the minimal performance threshold worker i must meet for promotion, Promote $\mathrm{e}_{\mathrm{i}}$ is a binary promotion indicator, $\mathbf{X}_{\mathrm{i}}$ is a vector of worker characteristics, $\mathbf{F}_{\mathrm{i}}$ is a vector of firm characteristics, $\mathrm{P}_{0 \mathrm{i}}$ denotes the performance of worker i's competitors, and the $\varepsilon$ 's follow a multivariate normal distribution with mean vector $\mathbf{0}$ and covariance matrix $\boldsymbol{\Sigma}{ }^{28}$ The model can be estimated via maximum likelihood. If relative performance determines promotions then $\gamma_{3}>0$, whereas if absolute performance determines promotions then $\gamma_{3}=0$. Within this empirical framework, Table 1 illustrates the parametric predictions implied by all of the models in Figure 1.

${ }^{28}$ Although identification requires only that one variable in the $\mathrm{S}^{*}$ equation be excluded from the $\mathrm{P}$ equation, in this case the entire vector $\mathbf{F}_{\mathrm{i}}$ is excluded. In the next section I elaborate on this assumption and consider a less stringent assumption. 
Table 1: Predictions of Alternative Models of Promotion

\begin{tabular}{|l|c|c|}
\hline & $\begin{array}{c}\text { Relative } \\
\text { Performance } \\
\left(\gamma_{3}>0\right)\end{array}$ & $\begin{array}{c}\text { Opposing } \\
\text { Responses } \\
\left(\sigma_{12}<0\right)\end{array}$ \\
\hline Performance Standards & $\gamma_{3}=0$ & $\sigma_{12}=0$ \\
\hline No Endogenous Worker Choice & $\gamma_{3}=0$ & $\sigma_{12}=0$ \\
Endogenous Worker Effort & $\gamma_{3}=0$ & $\sigma_{12} \gtreqless 0$ \\
Endogenous Worker Human Capital Investment & & \\
\hline Internal Promotion Competitions & $\gamma_{3}>0$ & $\sigma_{12}<0$ \\
\hline Classic Tournaments with Endogenous Effort & $\gamma_{3}>0$ & $\sigma_{12}>0$ \\
Market-Based Tournaments & $\gamma_{3}>0$ & $\sigma_{12}<0$ \\
Endogenous Worker Effort & \\
\hline \multicolumn{2}{|l}{ Endogenous Worker Human Capital Investment } &
\end{tabular}

Two points are worth noting. First, if the goal is simply to conduct the relative-versusabsolute performance test, then the promotion equation can be estimated in isolation rather than jointly with the $\mathrm{P}$ and $\mathrm{S}^{*}$ equations, as in subsection 7.1. Second, the $\mathrm{P}$ and $\mathrm{S}^{*}$ equations must be estimated jointly, since otherwise $\sigma_{12}$ cannot be estimated. An additional reason for conducting joint estimation is that if the $\mathrm{P}$ equation is estimated individually, as is typically done in the literature, then the estimate of $\alpha_{1}$ (i.e. incentive effects of promotions) will be biased.

\section{Empirical Evidence}

The system of equations from the preceding section has been estimated in DeVaro (2006a,b), though the goal in those papers was only to test the implications of the classic tournament model rather than distinguishing among the six alternative promotions models in Figure 1. In light of the new theoretical results from the preceding sections, the empirical results in the two earlier papers can be given new interpretations. Those studies used two subsamples of recently hired workers from the Multi-City Study of Urban Inequality (MCSUI). DeVaro (2006b) considered a subsample of 632 "skilled" workers, whereas DeVaro (2006a) considered a more highly-skilled sample of 215 professionals. Both studies found evidence of $\gamma_{3}>0$, suggesting internal promotions based on relative performance, so I restrict the following discussion to the left branch of Figure 1 and to the evidence concerning $\sigma_{12}$. Both studies also 
found evidence of $\alpha_{1}>0$, consistent with the incentive effects of promotions that have been documented in the previous literature, and the simultaneous-equations estimation approach in these two studies allowed for unbiased estimation of this parameter. ${ }^{29}$

First consider DeVaro (2006b), which found $\sigma_{12}<0$ and interpreted this evidence as consistent with classic tournaments. ${ }^{30}$ In light of the new results from the preceding sections, if we restrict our attention to tournament models in which promotions serve as incentives for workers to invest in effort, then the empirical result $\sigma_{12}<0$ conflicts with the prediction $\sigma_{12}>0$ of the market-based model. Waldman (2011) surveys the extensive empirical literature testing the predictions of the classic tournament model and concludes that most of the findings in the literature are consistent with that approach but that all but one of those predictions are also consistent with the market-based approach. The one exception he notes is empirical evidence of a convex wage structure across hierarchical levels. This prediction arises naturally from the classic model as shown in the multi-round analysis by Rosen (1986). In contrast, Waldman notes that although there are no multi-round market-based tournament models, there is no clear reason why convex wage structures should emerge as a robust prediction of market-based tournaments. I am reluctant to interpret this difference between the two models as offering a distinguishing empirical test, for two reasons. First, the market-based approach has not been developed in a multi-round context that would yield a prediction regarding convexity or the lack of it; so whereas classic tournaments predict convexity, market-based tournaments currently offer no prediction. Second, Waldman (2011) predicts that even the market-based model could generate a convex wage structure if the signal associated with a promotion was larger for promotions higher up the job ladder. The present analysis offers a sharp distinction between the two tournament models, given that one predicts a negative sign on $\sigma_{12}$ and the other a positive sign.

\footnotetext{
${ }^{29}$ Other representative studies that found evidence that performance is increasing in the size of the prize include Ehrenberg and Bognanno (1990a,b), Becker and Huselid (1992), and Audas, Barmby, and Treble (2004).

${ }^{30}$ Specifically, DeVaro (2006b) found $\sigma_{12}=-0.091, \gamma_{3}=1.496$, and $\alpha_{1}=0.591$, where the estimate of $\gamma_{3}$ was statistically significant at the one percent level and the other two parameters were significant at the ten percent level. In subsequent work concerning the difference between nonprofits and for-profits, DeVaro and Brookshire (2007) found that when the 81 nonprofits were dropped from the sample of 632 used in DeVaro (2006b), the results strengthened slightly from the standpoint of classic tournament theory, i.e. $\sigma_{12}=-0.118, \gamma_{3}=1.633$, and $\alpha_{1}=0.709$, with the estimate of $\alpha_{1}$ attaining statistical significance at the five percent level and the other two estimates remaining at their original significance levels. The fact that the results are somewhat stronger when the sample is restricted to for-profits is consistent with the theory proposed in DeVaro and Brookshire (2007) that for-profits are more likely than nonprofits to rely on promotion schemes such as classic tournaments to create incentives.
} 
When comparing classic and market-based tournaments the most appropriate comparison may be the one made in the preceding paragraph that restricts attention to models in which workers choose effort. This is because the stochastic component of worker performance in sections 2 and 4 share the same interpretation, whereas the interpretation differs in section 6. This matters because the test based on $\sigma_{12}$ assumes that the interpretation of $\mathrm{u}$ (and therefore its variance, $\theta$ ) is basically the same across the models being compared. With this caveat in mind, if the class of tournament models is broadened to include those in which promotions induce human capital investments, then the empirical finding of $\sigma_{12}<0$ in DeVaro (2006b) is consistent with both classic tournaments and market-based tournaments with human capital investments. Furthermore, if attention is restricted to the class of market-based tournaments, then the evidence favors the approach in which workers make human capital investments rather than effort choices.

Next consider DeVaro (2006a). That study also found $\sigma_{12}<0$, though the result was statistically insignificant so the null hypothesis of $\sigma_{12}=0$ could not be rejected. I will offer two interpretations of this result in light of the present analysis. The first interpretation is that the cross section represents a mix of the different types of internal promotion competitions in the left branch of Figure 1. Estimating $\sigma_{12}$ requires data spanning multiple promotion systems, which would usually require data spanning multiple firms. Suppose that in the population, some firms conduct market-based tournaments with endogenous worker effort (for which $\sigma_{12}>0$ ) whereas others conduct either of the other types of tournaments (for which $\sigma_{12}<0$ ). When the different types of firms are pooled in the cross section, their relative prevalence will determine the estimate of $\sigma_{12}$. The former type of tournaments would tend to increase $\sigma_{12}$ in estimation, whereas the latter types would tend to decrease $\sigma_{12}$, so that the two effects are roughly offsetting, producing a negative but statistically insignificant estimate of $\sigma_{12}$. This interpretation would say that in the more highly skilled subsample of professionals the market-based mechanism is a more powerful force than in the skilled subsample. Now consider a second interpretation. I view the result for skilled workers in DeVaro (2006a) concerning $\sigma_{12}$ as less reliable than the corresponding result for professionals in DeVaro (2006b), because the latter study used a considerably larger sample size, a more complete set of controls, an econometric model that was generalized to allow for measurement errors in $\mathrm{S}^{*}$ and $\mathrm{P}$, and a less stringent identifying 
assumption. These factors could potentially explain the lack of statistical significance of $\sigma_{12}<0$ in the professional subsample. In that case, the true results for professionals might match those for skilled workers, even though the statistical result is not strong enough to confirm this.

Identification of the $\mathrm{P}$ equation in both studies was achieved by excluding the firm characteristics appearing in the $\mathrm{S}^{*}$ equation from the $\mathrm{P}$ equation. The rationale for this derives from the fact that the data are a sample of recently hired workers. In addition to knowing little about the firm, the typical new hire will have experience with only a small number of previous employers, if any at all. In contrast, the firm possesses the relevant institutional history of the organization and knows how certain worker-types perform in given positions. This puts the firm at an advantage relative to a newly hired worker in assimilating information about firm characteristics into a decision function. DeVaro (2006b) also considered a less restrictive identifying assumption in which all firm characteristics in $\mathbf{F}_{\mathrm{i}}$ except union status were included in the $\mathrm{P}$ equation, finding similar results. ${ }^{31}$

\section{A New Test to Distinguish Between Classic and Market-Based Tournaments}

Given that the two tests I propose cannot distinguish classic tournaments with effort choices from market-based tournaments with human capital investments, it is worth considering alternative means by which these two models might be distinguished in future empirical research. I now propose such a test. The basic logic for the new test resembles the opposing responses test from the preceding two sections in the sense that I will show that the two tournament models differ in how the choice variables of workers and the firm respond to shifts in a theoretical parameter. However, in contrast to the opposing responses test described in earlier sections the parameter will no longer be the variance of the stochastic component of worker performance, and we will need to consider a different function of the firm's choice variables.

Focusing on two-player tournaments for simplicity, begin by noting that both models feature a strictly convex cost function, $\mathrm{C}(\mathrm{z})$, with $\mathrm{C}(0)=0$ and $\mathrm{C}^{\prime}(\mathrm{z})=0$, capturing the subordinate's disutility of the choice variable, $z$. Let $\xi$ be a parameter that affects $C(z)$, either increasing or decreasing the worker's total and marginal costs of $\mathrm{z}$, and assume that $\xi$ is observed

\footnotetext{
${ }^{31}$ The sample size in DeVaro (2006a) was not large enough to support estimation using this less stringent identifying assumption.
} 
by workers and the firm when their decisions are made. If $\xi$ is incentives-enhancing then $\partial \mathrm{C}(\mathrm{z}) / \partial \xi<0$ and $\partial \mathrm{C}^{\prime}(\mathrm{z}) / \partial \xi<0$, whereas if $\xi$ is incentives-depressing then $\partial \mathrm{C}(\mathrm{z}) / \partial \xi>0$ and $\partial \mathrm{C}^{\prime}(\mathrm{z}) / \partial \xi>0$. Without loss of generality, I consider the incentives-enhancing case henceforth. Note that $\xi$ is a theoretical parameter that is assumed to vary across tournaments in cross sectional data. The test requires that the researcher have data on at least one measure of $\xi$. As an example of such a variable, some companies (e.g. Google, Adobe, and SAS) provide their employees with free or subsidized snacks and meals throughout the day. One of the rationales for such practices is that they can be expected to lower workers' costs of exerting productive effort. Thus, one measure of $\xi$ would be the generosity of employer snack and meal subsidies.

Given a measure of $\xi$, one might be tempted to follow the same approach as in the preceding two sections, but using $\xi$ rather than $\theta$. That is, one would first determine whether the responses of effort and the spread to changes in $\xi$ differed between the two types of tournaments. Assuming the pattern of responses of the choice variables to changes in $\xi$ differed between the two models, one would then go to the data to see which of the models was empirically supported. It turns out that this approach would not work because, as I show below, the responses of effort and the spread to changes in $\xi$ do not differ between the two models. However, suppose that instead of focusing on the wage spread, i.e. $S^{*}=W_{m}-W_{s}$, we focus on the average wage between job levels, which is a subordinate's expected wage, i.e. $\mathrm{L}^{*}=\left(\mathrm{W}_{\mathrm{m}}+\right.$ $\mathrm{W}_{\mathrm{s}}$ )/2. The main result is given in the following proposition, showing that the response of $\mathrm{L}^{*}$ to shifts in $\xi$ differs between the two models, producing a testable implication:

Proposition 5: When $\xi$ is incentives-enhancing the following results hold concerning the equilibria of both tournament models: $:^{32}$

(i) In both models, $\partial \mathrm{z}^{*} / \partial \xi>0$ and $\partial \mathrm{S}^{*} / \partial \xi=0$.

(ii) In the market-based model with human capital choices, $\mathrm{L}^{*}$ is a linear function of $\mathrm{h}^{*}$, and $\partial \mathrm{L}^{*} / \partial \xi=\mathrm{V}_{\mathrm{H}} \partial \mathrm{L}^{*} / \partial \mathrm{h}^{*}>0$ so that $\xi$ influences $\mathrm{L}^{*}$ only via its effect on $\mathrm{h}^{*}$.

(iii) In the classic model with effort choices, $\mathrm{L}^{*}$ is a nonlinear function of $\mathrm{e}^{*}$, and $\partial \mathrm{L}^{*} / \partial \xi=$ $\mathrm{C}^{\prime}\left(\mathrm{e}^{*}\right)\left(\partial \mathrm{e}^{*} / \partial \xi\right)+\partial \mathrm{C}\left(\mathrm{e}^{*}\right) / \partial \xi$ so that $\xi$ influences $\mathrm{L}^{*}$ both via its effect on $\mathrm{e}^{*}$ and also directly via its effect on $\mathrm{C}\left(\mathrm{e}^{*}\right)$ for a given $\mathrm{e}^{*}$.

Point (i) says that the responses of $\mathrm{z}^{*}$ and $\mathrm{S}^{*}$ to changes in $\xi$ do not differ between the two

\footnotetext{
${ }^{32}$ The proposition could be recast in the obvious way to handle the incentives-depressing case.
} 
models. This means that a distinguishing empirical tests based on $\xi$ cannot be based on the choice variables $z^{*}$ and $S^{*}$. Points (ii) and (iii) create the basis for a distinguishing test based on responses in the choice variable $\mathrm{L}^{*}$ (rather than $\mathrm{S}^{*}$ ) to changes in $\xi$. Point (ii) says that in the market-based model with human capital investments, changes in $\xi$ influence the average wage only by affecting the worker's optimal choice of human capital. In contrast, point (iii) says that in the classic model changes in $\xi$ influence the average wage both by affecting the worker's optimal effort choice and by directly affecting the worker's effort cost function. ${ }^{33}$ The basic logic for the difference between the two models in how $\mathrm{L}^{*}$ responds to changes in $\xi$ is that in the classic model, unlike in the market-based model, the average wage is determined by the worker's participation constraint, i.e. $\mathrm{L}^{*}=\mathrm{C}\left(\mathrm{e}^{*}\right)$. From the participation constraint, the two channels of influence of $\xi$ on $\mathrm{L}^{*}$ are immediately apparent, given that shifts in $\xi$ change the function, $\mathrm{C}(\mathrm{e})$, and also the equilibrium effort choice, $\mathrm{e}^{*}$. In contrast, in the market-based model, since in equilibrium the average wage is not determined by the worker's participation constraint, the worker's cost function is of no direct relevance to $\mathrm{L}^{*}$. Thus, shifts in $\xi$ affect $\mathrm{L}^{*}$ only by changing the equilibrium human capital investment, $\mathrm{h}^{*}$.

I now translate Proposition 5 into a testable implication, which requires a systems-based estimation approach. Starting with the market-based model, recall that in equilibrium $\mathrm{L}_{\mathrm{i}}{ }^{*}=$ $\mathrm{V}_{\mathrm{H}}\left(\mathrm{h}^{*}(\mathrm{~V})+0.5\left(\mathrm{E}\left[\mathrm{u}_{\mathrm{i}(2)}\right]+\mathrm{E}\left[\mathrm{u}_{\mathrm{i}(1)}\right]\right)\right.$, where $\mathrm{i}$ indexes firms (or tournaments) in a cross section. Note in this expression that a subscript $\mathrm{i}$ appears on the expected values of the order statistics of $\mathrm{u}_{\mathrm{i}}$ given that the variance of $u_{i}$, i.e. $\theta_{i}$, varies across tournaments in the sample. Thus, the term $0.5\left(E\left[u_{i(2)}\right]+E\left[u_{i(1)}\right]\right)$ gets subsumed into the regression disturbance given that the econometrician typically cannot observe $\theta_{\mathrm{i}}$, as was the case for $\theta_{\mathrm{i}}$ in the preceding two sections. This yields the following regression: ${ }^{34}$

\footnotetext{
${ }^{33}$ For example, suppose $\mathrm{C}(\mathrm{z})=\alpha \mathrm{z}^{\lambda} / \xi$, where $\xi>0, \alpha>0$, and $\lambda>1$, so $\mathrm{C}^{\prime}(\mathrm{z})=\alpha \lambda \mathrm{z}^{\lambda-1} / \xi$ and $\partial \mathrm{C}(\mathrm{z}) / \partial \xi=-\alpha \mathrm{z}^{\lambda} / \xi^{2}$. In the classic model, $\mathrm{L}^{*}=\alpha \mathrm{e}^{* \lambda} / \xi$ where $\mathrm{e}^{*}=[\xi \operatorname{Sg}(0) /(\alpha \lambda)]^{1 /(\lambda-1)}$, so that $\xi$ affects $\mathrm{L}^{*}$ both directly and also indirectly via its effect on $\mathrm{e}^{*}$. Given that (i) $\mathrm{C}^{\prime}\left(\mathrm{e}^{*}\right)$ is zero at $\mathrm{e}^{*}=0$ and positive and increasing in $\mathrm{e}^{*}$ for $\mathrm{e}^{*}>0$, (ii) $\partial \mathrm{e}^{*} / \partial \xi$ is positive, and (iii) $\partial \mathrm{C}\left(\mathrm{e}^{*}\right) / \partial \xi$ is zero for $\mathrm{e}^{*}=0$ and negative for $\mathrm{e}^{*}>0$, we have that $\partial \mathrm{L}^{*} / \partial \xi$ is 0 when $\mathrm{e}^{*}=0$, then increasing in $\mathrm{e}^{*}$ until a peak where $\partial^{2} \mathrm{~L}^{*} /\left(\partial \xi \partial \mathrm{e}^{*}\right)=0$, then monotonically decreasing in $\mathrm{e}^{*}$ thereafter so that $\partial \mathrm{L}^{*} / \partial \xi<0$ for $\mathrm{e}^{*}$ sufficiently large. So in the classic model the effect on the subordinate's expected wage of a marginal increase in $\xi$, i.e. $\partial \mathrm{L}^{*} / \partial \xi$, is non-monotonic in $\mathrm{e}^{*}$. For sufficiently low levels of $\mathrm{e}^{*}$, it is positive and increasing in $\mathrm{e}^{*}$. Then it is positive and decreasing in $\mathrm{e}^{*}$, and ultimately negative and decreasing in $\mathrm{e}^{*}$. In contrast, in the market-based model $\partial \mathrm{L}^{*} / \partial \xi=\mathrm{V}_{\mathrm{H}}[\xi \mathrm{Sq}(0) /(\alpha \lambda)]^{1 /(\lambda-1)}>0$, which is not a function of $\mathrm{h}^{*}$.

${ }^{34}$ To simplify the notation, control variables are suppressed throughout this section.
} 
$\mathrm{L}_{\mathrm{i}}^{*}=\omega_{0}+\omega_{1} \mathrm{~h}_{\mathrm{i}}^{*}+\varepsilon_{1 \mathrm{i}}$

Since $h_{i}{ }^{*}$ is endogenous, there is a second equation:

$\mathrm{h}_{\mathrm{i}}^{*}=\eta_{0}+\eta_{1} \mathrm{~S}_{\mathrm{i}}^{*}+\eta_{2} \xi_{\mathrm{i}}+\varepsilon_{2 \mathrm{i}}$.

The spread, $\mathrm{S}_{\mathrm{i}}{ }^{*}$, is also endogenous, so there is a third equation describing it, as in the preceding two sections. Given point (i) of Proposition 5, $\xi_{\mathrm{i}}$ does not appear in the equation for $\mathrm{S}_{\mathrm{i}}{ }^{*}$.

Substituting the equation for $\mathrm{S}_{\mathrm{i}}{ }^{*}$ into the equation for $\mathrm{h}_{\mathrm{i}}{ }^{*}$ yields the following reduced form:

$\mathrm{h}_{\mathrm{i}}{ }^{*}=\varphi_{0}+\varphi_{1} \xi_{\mathrm{i}}+\varepsilon_{2 \mathrm{i}}$, where $\varepsilon_{2 \mathrm{i}}$ is redefined to subsume the disturbance from the $\mathrm{S}_{\mathrm{i}}{ }^{*}$ equation.

The system involving the $\mathrm{L}_{\mathrm{i}}{ }^{*}$ equation and the reduced form for $\mathrm{h}_{\mathrm{i}}{ }^{*}$ is exactly identified given that $\xi_{\mathrm{i}}$ appears in the $\mathrm{h}_{\mathrm{i}}{ }^{*}$ equation but not in the $\mathrm{L}_{\mathrm{i}}{ }^{*}$ equation, and this is implied by part (ii) of Proposition 5. If the econometrician has data on $\mathrm{h}_{\mathrm{i}}{ }^{*}$ this system can be estimated. But assume, as is typically the case, that the econometrician has data on worker performance but not worker choice variables. Then $\mathrm{h}_{\mathrm{i}}{ }^{*}=\mathrm{P}_{\mathrm{i}}-\mathrm{u}_{\mathrm{i}}$ can be substituted into both regressions, yielding the following "market-based system" where the disturbances $\varepsilon_{1 \mathrm{i}}$ have been redefined to include $\mathrm{u}_{\mathrm{i}}$ :

$\mathrm{L}_{\mathrm{i}}^{*}=\beta_{0}+\beta_{1} \mathrm{P}_{\mathrm{i}}+\varepsilon_{1 \mathrm{i}}$

$\mathrm{P}_{\mathrm{i}}=\alpha_{0}+\alpha_{1} \xi_{\mathrm{i}}+\varepsilon_{2 \mathrm{i}}$

This market-based system makes clear that, as in point (ii) of Proposition $5, \xi_{\mathrm{i}}$ affects $\mathrm{L}_{\mathrm{i}}{ }^{*}$ only via its effect on $\mathrm{h}_{\mathrm{i}}{ }^{*}$ (and therefore $\mathrm{P}_{\mathrm{i}}$ ). There is no direct channel of influence of $\xi_{\mathrm{i}}$ on $\mathrm{L}_{\mathrm{i}}{ }^{*}$, hence $\xi_{\mathrm{i}}$ 's exclusion from the $\mathrm{L}_{\mathrm{i}}{ }^{*}$ equation.

Next consider the classic model, where the participation constraint implies $\mathrm{L}_{\mathrm{i}}{ }^{*}=\mathrm{C}\left(\mathrm{e}_{\mathrm{i}}{ }^{*}\right) . \mathrm{A}$ linear approximation of $\mathrm{C}(\mathrm{e})$ yields the following regression:

$\mathrm{L}_{\mathrm{i}}^{*}=\omega_{0}+\omega_{1} \mathrm{e}_{\mathrm{i}}^{*}+\omega_{2} \xi_{\mathrm{i}}+\varepsilon_{1 \mathrm{i}}$

Since $\mathrm{e}_{\mathrm{i}}{ }^{*}$ is endogenous, there is a second equation:

$\mathrm{e}_{\mathrm{i}}^{*}=\eta_{0}+\eta_{1} \mathrm{~S}_{\mathrm{i}}^{*}+\eta_{2} \xi_{\mathrm{i}}+\varepsilon_{2 \mathrm{i}}$.

The spread, $\mathrm{S}_{\mathrm{i}}{ }^{*}$ is endogenous, so there is a third equation describing it, as in the preceding two sections. Given point (i) of Proposition $5, \xi_{\mathrm{i}}$ does not appear in the equation for $\mathrm{S}_{\mathrm{i}}{ }^{*}$. Substituting the equation for $S_{i}{ }^{*}$ into the preceding equation for $\mathrm{e}_{\mathrm{i}}^{*}$ yields the following reduced form: $\mathrm{e}_{\mathrm{i}}{ }^{*}=\varphi_{0}+\varphi_{1} \xi_{\mathrm{i}}+\varepsilon_{2 \mathrm{i}}$ where $\varepsilon_{2 \mathrm{i}}$ is redefined to include the disturbance from the $\mathrm{S}_{\mathrm{i}}{ }^{*}$ equation.

In contrast to the market-based system, the system involving the $\mathrm{L}_{\mathrm{i}}{ }^{*}$ equation and the reduced form for $\mathrm{e}_{\mathrm{i}}{ }^{*}$ is not identified given that $\xi_{\mathrm{i}}$ appears in both equations via part (iii) of 
Proposition 5. Assume, as is typically the case, that the econometrician has data on worker performance but not worker choice variables. Then $\mathrm{e}_{\mathrm{i}}{ }^{*}=\mathrm{P}_{\mathrm{i}}-\mathrm{u}_{\mathrm{i}}$ can be substituted into both regressions. Furthermore, to resolve the identification problem, assume the econometrician has access to an exogenous variable, $\mathrm{I}_{\mathrm{i}}$, that determines subordinate performance but that affects the average compensation between job levels only via subordinate performance. This gives rise to the following "classic system" where the disturbances $\varepsilon_{1 i}$ have been redefined:

$\mathrm{L}_{\mathrm{i}}^{*}=\beta_{0}+\beta_{1} \mathrm{P}_{\mathrm{i}}+\beta_{2} \xi_{\mathrm{i}}+\varepsilon_{1 \mathrm{i}}$ $\mathrm{P}_{\mathrm{i}}=\alpha_{0}+\alpha_{1} \xi_{\mathrm{i}}+\alpha_{1} \mathrm{I}_{\mathrm{i}}+\varepsilon_{2 \mathrm{i}}$

In this system, as in point (iii) of Proposition $5, \xi_{\mathrm{i}}$ affects $\mathrm{L}_{\mathrm{i}}{ }^{*}$ both via its effect on $\mathrm{e}_{\mathrm{i}}{ }^{*}$ (and therefore $\mathrm{P}_{\mathrm{i}}$ ) and also directly. Furthermore, the classic system nests the market-based system as the special case for which $\beta_{2}=0$.

To summarize, an empirical test based on Proposition 5 that allows classic tournaments to be distinguished from market-based tournaments with human capital investments would proceed as follows. First, assuming the disturbances $\varepsilon_{1 \mathrm{i}}$ and $\varepsilon_{2 \mathrm{i}}$ are jointly normal with mean vector $\mathbf{0}$ and covariance matrix $\boldsymbol{\Sigma}$, estimate the preceding classic system via maximum likelihood. Second, test the null hypothesis that $\beta_{2}=0$ against the alternative hypothesis that $\beta_{2}<0$ using a one-tailed test. Rejecting the null favors the classic tournament model, whereas failing to reject favors the market-based tournament model with endogenous human capital investments.

I close the section with four observations. First, the preceding test assumes crosssectional variation across tournaments so that $\mathrm{i}$ indexes tournaments and there is one worker observed per tournament. The method could also be applied to data in which there are observations on multiple workers per tournament and/or panel data. Second, justifying the choice of instrument, $\mathrm{I}_{\mathrm{i}}$, is facilitated by the fact that the classic tournament model assumes that $\mathrm{W}_{\mathrm{m}}$ and $\mathrm{W}_{\mathrm{s}}$ (and therefore $\mathrm{L}^{*}$ ) are chosen by the firm ex ante, before subordinates choose effort levels and, thus, before subordinate performance is determined. This timing provides a theoretical basis for exclusion restrictions that might otherwise not be obvious. Third, the fact that the test is based on $\mathrm{L}^{*}$ rather than $\mathrm{S}^{*}$ is interesting, since the previous literature has focused on the determinants of $S^{*}$ (given that the wage spread is what creates incentives) with little attention paid to the determinants of $\mathrm{L}^{*}$. This section illustrates that for the purpose of distinguishing 
between the two types of tournaments, studying the average wage between levels is more helpful than studying the wage spread between levels. Fourth, like earlier sections, this one highlights the usefulness of systems-based approaches that simultaneously account for worker and firm behavior in research that aims to distinguish among alternative theoretical models of promotions.

\section{Conclusion}

This study shows that the core theoretical models in the promotions literature can be distinguished empirically to a greater extent than previously recognized. The following four results are of particular interest. First, if we restrict attention to the class of models in which promotions create incentives for workers to exert effort, then the relative-versus-absolute performance test and the opposing responses test distinguish among classic tournaments, marketbased tournaments, and performance standards. The distinction between classic and marketbased models is particularly sharp in this case given that those models imply opposite predictions for the sign of $\sigma_{12}$, and this is an important result given that, as noted in Waldman (2011), most of the existing empirical evidence does not allow the two models to be distinguished. Second, if we restrict attention to market-based tournaments, then the model with worker effort choices can be sharply distinguished from the model with human capital investments, again due to opposite predictions on the sign of $\sigma_{12}$. Third, the two tests are insufficient for distinguishing classic tournaments from market-based tournaments with human capital investments, since both models exhibit the opposing responses property. However, fourth, these two tournament models can be empirically distinguished using a new test based on the average wage between job levels, and the new test provides guidance for future data collection and analysis.

In a broad cross section spanning many different markets and employer types, it is plausible that a blend of alternative promotion schemes might occur in the labor market. It is even possible that alternative schemes might operate simultaneously within the same firm, and on this basis Waldman (2011) recommends integrating classic and market-based tournament models in future theoretical work. The present analysis suggests that such an approach might help to better reconcile certain theoretical predictions with the evidence. For example, consider an integration of the market-based model with effort choices (which predicts $\sigma_{12}>0$, conflicting with the empirical evidence from section 8) and the classic tournament model. The classic 
mechanism in such an integration might allow the prediction $\sigma_{12}<0$ to emerge empirically (or would at least weaken the prediction $\sigma_{12}>0$ ) even though the strategic decisions of firms in setting wage spreads would be somewhat constrained by the actions of competing firms.

Prior to the present paper, theoretical predictions concerning $\theta$ either had not been derived or they had been derived but not highlighted and translated into testable implications. An advantage of the opposing responses test is that it allows predictions about $\theta$ (which would usually be unobserved to the econometrician) to be translated into a prediction about the sign of the parameter $\sigma_{12}$, which can be and has been estimated. As Table 1 illustrates, the opposing responses test is important for differentiating among alternative models of promotion. The test requires accounting for worker and firm behaviors simultaneously using systems-based econometric methods. The new test proposed in the preceding section also requires a (different) systems-based approach. In contrast, the empirical literature on promotions has historically relied on single-equation, non-structural estimation techniques. Overall, the analysis highlights the value of systems-based econometric methods in empirical work on promotions, and a priority for future research should be applying these methods to other data sets containing information related to the choice variables of workers and firms, as well as collecting new data that will support these methods.

\section{Appendix}

Proof of Proposition 1: Consider first the case without worker effort (i.e. $\alpha=\infty$ ). In this case, the subordinate always invests the minimum effort in the first period, so $\partial \mathrm{e}^{*} / \partial \theta=0$. In models such as Waldman (1984a) and DeVaro and Waldman (2011) that do not incorporate an effort choice, $\partial \mathrm{e}^{*} / \partial \theta$ does not exist. From Proposition 1 of Ghosh and Waldman (2010), $\mathrm{S}^{*} \equiv \mathrm{W}_{\mathrm{m}}-\mathrm{W}_{\mathrm{s}}=\left[\mathrm{d}_{\mathrm{m}}+\mathrm{c}_{\mathrm{m}} \eta^{+}\right]-\left[\mathrm{d}_{\mathrm{s}}+\mathrm{c}_{\mathrm{s}} \mathrm{a}_{\mathrm{L}} \mathrm{k}\right]$, where $\eta^{+}$is a critical threshold (or standard) that determines whether a subordinate is promoted to a managerial position in the second period. After observing subordinate i's first-period output, $\mathrm{y}_{\mathrm{i}}$, the firm promotes the worker in period 2 if $\eta^{\mathrm{e}}\left(\mathrm{y}_{\mathrm{i} 1}\right) \geq \eta^{+}$and retains the worker as a subordinate if $\eta^{\mathrm{e}}\left(\mathrm{y}_{\mathrm{i} 1}\right)<\eta^{+}$. The following equation defines $\eta^{+}:(1+\mathrm{F})\left[\mathrm{d}_{\mathrm{s}}+\mathrm{c}_{\mathrm{s}} \eta^{+}\right]-\left[\mathrm{d}_{\mathrm{s}}+\mathrm{c}_{\mathrm{s}} \mathrm{a}_{\mathrm{L}} \mathrm{k}\right]=(1+\mathrm{F})\left[\mathrm{d}_{\mathrm{m}}+\mathrm{c}_{\mathrm{m}} \eta^{+}\right]-\max \left\{\mathrm{d}_{\mathrm{s}}+\mathrm{c}_{\mathrm{s}} \eta^{+}, \mathrm{d}_{\mathrm{m}}+\mathrm{c}_{\mathrm{m}} \eta^{+}\right\}$. Since $\theta$ does not appear in this expression, $\eta^{+}$(and thus $S^{*}$ ) is not a function of $\theta$, so $\partial S^{*} / \partial \theta=0$. By a similar argument, $\partial \mathrm{S}^{*} / \partial \theta=0$ also holds in the model of Waldman (1984a) and its 
extensions such as DeVaro and Waldman (2011). If $\alpha<\infty$ so that subordinates might exert more than the minimum effort level of $\mathrm{e}_{\mathrm{L}}$ in the first period, $\partial \mathrm{S}^{*} / \partial \theta=0$ continues to hold, with the slight modification that the parameter $\mathrm{e}_{\mathrm{L}}$ appears throughout the expressions. The expressions for wages and $\eta^{+}$in this case are given in an earlier version of Ghosh and Waldman (2010). Q.E.D.

Proof of Proposition 2: First consider $\partial \mathrm{S}^{*} / \partial \theta$. Using the expressions for the subordinates' firstperiod output, the expressions for managerial and subordinate wages can be rewritten as:

$\mathrm{W}_{\mathrm{m}}=\mathrm{d}_{\mathrm{m}}+\mathrm{c}_{\mathrm{m}} \mathrm{k}\left[\mu_{\mathrm{m}} \mathrm{a}_{\mathrm{H}}+\left(1-\mu_{\mathrm{m}}\right) \mathrm{a}_{\mathrm{L}}\right]$

$\mathrm{W}_{\mathrm{s}}=\mathrm{d}_{\mathrm{s}}+\mathrm{c}_{\mathrm{s}} \mathrm{k}\left[\mu_{\mathrm{s}} \mathrm{a}_{\mathrm{H}}+\left(1-\mu_{\mathrm{s}}\right) \mathrm{a}_{\mathrm{L}}\right]$, where $\mu_{m} \equiv 2 \rho(1-\rho) \Phi\left[\left(a_{H}-a_{L}\right) /(2 \theta)^{0.5}\right]+\rho^{2}, \mu_{s} \equiv 2 \rho(1-\rho) \Phi\left[\left(a_{L}-a_{H}\right) /(2 \theta)^{0.5}\right]+\rho^{2}$, and $\Phi$ denotes the standard normal cumulative distribution function. Note that $\partial \mu_{\mathrm{m}} / \partial \theta=-2 \rho(1-\rho) \phi\left[\left(\mathrm{a}_{\mathrm{H}}-\mathrm{a}_{\mathrm{L}}\right) /(2 \theta)^{0.5}\left(\mathrm{a}_{\mathrm{H}}-\mathrm{a}_{\mathrm{L}}\right)(2 \theta)^{-0.5}<0\right.$, and $\partial \mu_{\mathrm{s}} / \partial \theta=2 \rho(1-\rho) \phi\left[\left(\mathrm{a}_{\mathrm{H}}-\mathrm{a}_{\mathrm{L}}\right) /(2 \theta)^{0.5}\right]\left(\mathrm{a}_{\mathrm{H}}-\mathrm{a}_{\mathrm{L}}\right)(2 \theta)^{-0.5}>0$, where $\phi($.$) denotes the standard normal$ density function. Defining the equilibrium wage spread, $\mathrm{S}^{*}$, as $\mathrm{S}^{*} \equiv \mathrm{W}_{\mathrm{m}}-\mathrm{W}_{\mathrm{s}}$, we have: $\mathrm{S}^{*}=\left(\mathrm{d}_{\mathrm{m}}-\mathrm{d}_{\mathrm{s}}\right)+\mathrm{ka}_{\mathrm{L}}\left[\mathrm{c}_{\mathrm{m}}-\mathrm{c}_{\mathrm{s}}\right]+\mathrm{k}\left(\mathrm{a}_{\mathrm{H}}-\mathrm{a}_{\mathrm{L}}\right)\left[\mathrm{c}_{\mathrm{m}} \mu_{\mathrm{m}}-\mathrm{c}_{\mathrm{s}} \mu_{\mathrm{s}}\right]$. This expression makes clear that $\partial \mathrm{S}^{*} / \partial \theta=\mathrm{k}\left(\mathrm{a}_{\mathrm{H}}-\mathrm{a}_{\mathrm{L}}\right)\left[\mathrm{c}_{\mathrm{m}} \partial \mu_{\mathrm{m}} / \partial \theta-\mathrm{c}_{\mathrm{s}} \partial \mu_{\mathrm{s}} / \partial \theta\right]<0$. Next consider $\partial \mathrm{e}^{*} / \partial \theta$. Worker i chooses first-period effort $\mathrm{e}_{\mathrm{i} 1}$ to maximize expected utility of $\mathrm{pW}_{\mathrm{m}}+\mathrm{W}_{\mathrm{s}}(1-\mathrm{p})-\alpha \mathrm{C}\left(\mathrm{e}_{\mathrm{i} 1}\right)$, where $\mathrm{p}$ is the probability that worker $\mathrm{i}$ is promoted. The first-order condition defining worker i's optimal effort, $\mathrm{e}_{\mathrm{i} 1}{ }^{{ }}{ }$, is: $\left(\mathrm{W}_{\mathrm{m}}-\mathrm{W}_{\mathrm{s}}\right) \partial \mathrm{p} / \partial \mathrm{e}_{\mathrm{i} 1}{ }^{*}-\alpha \mathrm{C}^{\prime}\left(\mathrm{e}_{\mathrm{i} 1}{ }^{*}\right)=0$. Expressions for $\mathrm{p}$ and $\partial \mathrm{p} / \partial \mathrm{e}_{\mathrm{i} 1}$ are as follows: $\mathrm{p}=\Phi\left[\left(\mathrm{a}_{\mathrm{H}}-\mathrm{a}_{\mathrm{L}}+\mathrm{e}_{\mathrm{i} 1}-\mathrm{e}_{\mathrm{j} 1}\right) /(2 \theta)^{0.5}\right] \rho(1-\rho)+\Phi\left[\left(\mathrm{a}_{\mathrm{L}}-\mathrm{a}_{\mathrm{H}}+\mathrm{e}_{\mathrm{i} 1}-\mathrm{e}_{\mathrm{j} 1}\right) /(2 \theta)^{0.5}\right] \rho(1-\rho)+$

$$
\begin{gathered}
\Phi\left[\left(\mathrm{e}_{\mathrm{i} 1}-\mathrm{e}_{\mathrm{j} 1}\right) /(2 \theta)^{0.5}\right]\left(1+2 \rho^{2}-2 \rho\right) \\
\partial \mathrm{p} / \partial \mathrm{e}_{\mathrm{i} 1}=\rho(1-\rho) \phi\left[\left(\mathrm{a}_{\mathrm{H}}-\mathrm{a}_{\mathrm{L}}+\mathrm{e}_{\mathrm{i} 1}-\mathrm{e}_{\mathrm{j} 1}\right)(2 \theta)^{-0.5}\right] /(2 \theta)^{0.5}+\rho(1-\rho) \phi\left[\left(\mathrm{a}_{\mathrm{L}}-\mathrm{a}_{\mathrm{H}}+\mathrm{e}_{\mathrm{i} 1}-\mathrm{e}_{\mathrm{j} 1}\right)(2 \theta)^{-0.5}\right] /(2 \theta)^{0.5}+
\end{gathered}
$$

$$
\left(1+2 \rho^{2}-2 \rho\right) \phi\left[\left(e_{i 1}-e_{j 1}\right)(2 \theta)^{-0.5}\right] /(2 \theta)^{0.5}>0
$$

From the preceding expression, it can be shown that $\partial^{2} \mathrm{p} /\left(\partial \mathrm{e}_{\mathrm{i} 1} \partial \theta\right)<0$. Applying implicit differentiation to the worker's first-order condition and assuming that the second-order condition is satisfied yields the result $\operatorname{sign}\left(\partial \mathrm{e}^{*} / \partial \theta\right)=\operatorname{sign}\left(\partial^{2} \mathrm{p} /\left(\partial \mathrm{e}_{\mathrm{i} 1} \partial \theta\right)\right)$. Thus, $\partial \mathrm{e}^{*} / \partial \theta<0$. Q.E.D.

Proof of Proposition 3: The worker's expected utilities given the choice of $h$ are as follows:

$\mathrm{E}(\mathrm{U} \mid \mathrm{h}=1)=\left[1-\left(\mathrm{u}^{*}-\mathrm{m}+\mathrm{a}\right) /(2 \mathrm{a})\right] \mathrm{W}_{\mathrm{m}}+\left[\left(\mathrm{u}^{*}-\mathrm{m}+\mathrm{a}\right) /(2 \mathrm{a})\right] \mathrm{W}_{\mathrm{s}}-\mathrm{c}$

$\mathrm{E}(\mathrm{U} \mid \mathrm{h}=0)=\left[1-\left(\mathrm{u}^{\prime}-\mathrm{m}+\mathrm{a}\right) /(2 \mathrm{a})\right] \mathrm{W}_{\mathrm{m}}+\left[\left(\mathrm{u}^{\prime}-\mathrm{m}+\mathrm{a}\right) /(2 \mathrm{a})\right] \mathrm{W}_{\mathrm{s}}$

The difference of these expectations can be expressed as follows: 
$\mathrm{E}(\mathrm{U} \mid \mathrm{h}=1)-\mathrm{E}(\mathrm{U} \mid \mathrm{h}=0)=\left(\mathrm{u}^{\prime}-\mathrm{u}^{*}\right)\left(\mathrm{W}_{\mathrm{m}}-\mathrm{W}_{\mathrm{s}}\right) /\left(2(3 \theta)^{0.5}\right)-\mathrm{c}$

Given that $\mathrm{u}^{\prime}-\mathrm{u}^{*} \geq 0$, if $\mathrm{W}_{\mathrm{m}}-\mathrm{W}_{\mathrm{s}}$ is sufficiently small then $\mathrm{E}(\mathrm{U} \mid \mathrm{h}=1)-\mathrm{E}(\mathrm{U} \mid \mathrm{h}=0)<0$ so that the worker chooses $\mathrm{h}=0$, whereas if $\mathrm{W}_{\mathrm{m}}-\mathrm{W}_{\mathrm{s}}$ is sufficiently large then the worker chooses $\mathrm{h}=1$. The firm chooses values of $\mathrm{W}_{\mathrm{m}}$ and $\mathrm{W}_{\mathrm{s}}$ that induce the worker to make the investment choice that maximizes the firm's expected profit. As discussed in Prendergast (1993), the worker's incentive compatibility constraint binds in equilibrium. In the present extension of the model, that implies $\mathrm{F} \equiv\left(\mathrm{u}^{\prime}-\mathrm{u}^{*}\right)\left(\mathrm{W}_{\mathrm{m}}-\mathrm{W}_{\mathrm{s}}\right)-2 \mathrm{c}(3 \theta)^{0.5}=0$. Letting $\mathrm{S}^{*}$ denote the equilibrium spread, $\mathrm{W}_{\mathrm{m}}$ $-\mathrm{W}_{\mathrm{s}}$, implicit differentiation of $\mathrm{F}=0$ yields $\partial \mathrm{S}^{*} / \partial \theta=-(\partial \mathrm{F} / \partial \theta) /\left(\partial \mathrm{F} / \partial \mathrm{S}^{*}\right)=3 \mathrm{c}(3 \theta)^{-0.5} /\left(\partial \mathrm{F} / \partial \mathrm{S}^{*}\right)$, where $\partial \mathrm{F} / \partial \mathrm{S}^{*}=\left(\partial \mathrm{u}^{\prime} / \partial \mathrm{S}^{*}-\partial \mathrm{u}^{*} / \partial \mathrm{S}^{*}\right) \mathrm{S}^{*}+\left(\mathrm{u}^{\prime}-\mathrm{u}^{*}\right)$. Given that $\mathrm{u}^{\prime}-\mathrm{u}^{*}$ and $\mathrm{S}^{*}$ are non-negative, the sign of $\partial \mathbf{u}^{\prime} / \partial \mathrm{S}^{*}-\partial \mathrm{u}^{*} / \partial \mathrm{S}^{*}$ determines the sign of $\partial \mathrm{S}^{*} / \partial \theta$. Applying implicit differentiation to the firm's following two incentive compatibility conditions yields $\partial \mathrm{u}^{\prime} / \partial \mathrm{S} \geq 0$ and $\partial \mathrm{u}^{*} / \partial \mathrm{S} \geq 0$ : $\mathrm{y}_{\mathrm{m}}\left(0, \mathrm{u}^{\prime}\right)-\mathrm{y}_{\mathrm{s}}\left(0, \mathrm{u}^{\prime}\right)-\mathrm{S}^{*}=0$ and $\mathrm{y}_{\mathrm{m}}\left(1, \mathrm{u}^{*}\right)-\mathrm{y}_{\mathrm{s}}\left(1, \mathrm{u}^{*}\right)-\mathrm{S}=0$. However, the sign of $\partial \mathrm{u}^{\prime} / \partial \mathrm{S}^{*}-\partial \mathrm{u}^{*} / \partial \mathrm{S}^{*}$ can be either negative or positive, as the following example with linear production functions illustrates. Assume the production functions are as follows: $\mathrm{y}_{\mathrm{m}}(0, \mathrm{u})=\mathrm{a}_{0}+\mathrm{b}_{0} \mathrm{u} ; \mathrm{y}_{\mathrm{s}}(0, \mathrm{u})=\mathrm{c}_{0}+\mathrm{d}_{0} \mathrm{u}$; $\mathrm{y}_{\mathrm{m}}(1, \mathrm{u})=\mathrm{a}_{1}+\mathrm{b}_{1} \mathrm{u} ; \mathrm{y}_{\mathrm{s}}(1, \mathrm{u})=\mathrm{c}_{1}+\mathrm{d}_{1} \mathrm{u}$. Also let $\mathrm{b}_{0} \geq \mathrm{d}_{0} \geq 0, \mathrm{~b}_{1} \geq \mathrm{d}_{1} \geq 0, \mathrm{a}_{0} \geq \mathrm{c}_{0}, \mathrm{a}_{1} \geq \mathrm{c}_{1}$, and $\mathrm{a}_{1}-\mathrm{a}_{0}+$ $\left(b_{1}-d_{1}\right) u>c_{1}-c_{0}+\left(b_{0}-d_{0}\right) u \forall u$, so that the two key assumptions of the model are satisfied. Without loss of generality, suppose $b_{0}-d_{0}-\left(b_{1}-d_{1}\right)>0$. The firm's two incentive compatibility conditions determine $\mathrm{u}^{\prime}$ and $\mathrm{u}^{*}$ as follows:

$\mathrm{u}^{\prime}=\left(\mathrm{S}-\mathrm{a}_{0}+\mathrm{c}_{0}\right) /\left(\mathrm{b}_{0}-\mathrm{d}_{0}\right)$ and $\mathrm{u}^{*}=\left(\mathrm{S}-\mathrm{a}_{1}+\mathrm{c}_{1}\right) /\left(\mathrm{b}_{1}-\mathrm{d}_{1}\right)$. These expression imply:

$\partial \mathrm{u}^{\prime} / \partial \mathrm{S}-\partial \mathrm{u}^{*} / \partial \mathrm{S}=1 /\left(\mathrm{b}_{0}-\mathrm{d}_{0}\right)-1 /\left(\mathrm{b}_{1}-\mathrm{d}_{1}\right)<0$. Return to the last inequality expression that is required to ensure the two key assumption of the model are satisfied. For this expression to hold for all $\mathrm{u}$ requires that it hold when $\mathrm{u}=0$ and when $\mathrm{u}$ assumes its maximum value of $\mathrm{m}+\mathrm{a}$. To satisfy it when $\mathrm{u}=0$, we need $\left(\mathrm{a}_{1}-\mathrm{c}_{1}\right)-\left(\mathrm{a}_{0}-\mathrm{c}_{0}\right)>0$. To satisfy it when $\mathrm{u}=\mathrm{m}+\mathrm{a}$, we need $\left(a_{1}-c_{1}\right)-\left(a_{0}-c_{0}\right)>\left[\left(b_{0}-d_{0}\right)-\left(b_{1}-d_{1}\right)\right](m+a)$.

Recalling that $\partial \mathrm{F} / \partial \mathrm{S}=\left(\partial \mathrm{u}^{\prime} / \partial \mathrm{S}-\partial \mathrm{u}^{*} / \partial \mathrm{S}\right) \mathrm{S}+\left(\mathrm{u}^{\prime}-\mathrm{u}^{*}\right)$, for $\partial \mathrm{F} / \partial \mathrm{S}<0$ we need the first inequality: $-2 \mathrm{~S}\left[\left(\mathrm{~b}_{0}-\mathrm{d}_{0}\right)-\left(\mathrm{b}_{1}-\mathrm{d}_{1}\right)\right]-\left(\mathrm{a}_{0}-\mathrm{c}_{0}\right)\left(\mathrm{b}_{1}-\mathrm{d}_{1}\right)+\left(\mathrm{a}_{1}-\mathrm{c}_{1}\right)\left(\mathrm{b}_{0}-\mathrm{d}_{0}\right)<0$ And for the two key assumptions to hold, as noted above, we need the second inequality: $\left(a_{1}-c_{1}\right)-\left(a_{0}-c_{0}\right)>\left[\left(b_{0}-d_{0}\right)-\left(b_{1}-d_{1}\right)\right](m+a)$

Parameter values can be chosen to satisfy the second inequality. The first inequality can then be 
made to hold or to fail by changing the value of $\mathrm{S}$, with larger values of the spread making the inequality more likely to hold. Thus, the prediction for the sign of $\partial \mathrm{S}^{*} / \theta$ is ambiguous. Q.E.D.

Proof of Proposition 4: Let $\mathrm{u}$ be distributed symmetrically and continuously on the support $[\alpha, \beta]$, and let $f_{u}(u)$ denote its density function. Assume that $\alpha$ is sufficiently high to ensure that the equilibrium involves no turnover. Assuming $\mathrm{C}(\mathrm{h})=0.5 \mathrm{~h}^{2}$ for simplicity, $\mathrm{h}^{*}$ is proportional to $\mathrm{q}(0)\left[\mathrm{E}\left(\mathrm{u}_{(2)}\right)-\mathrm{E}\left(\mathrm{u}_{(1)}\right)\right]$. Let $\mathrm{x}$ be a random variable distributed continuously and symmetrically on $[0,1]$ with density function $f_{x}$, and let $u=(\beta-\alpha) x+\alpha$. Since $x$ (and therefore $u$ ) is distributed symmetrically, we can assume $\alpha=0$ without loss of generality since it is straightforward to show that neither $\mathrm{q}(0)$ nor $\mathrm{E}\left(\mathrm{u}_{(2)}\right)-\mathrm{E}\left(\mathrm{u}_{(1)}\right)$ vary with $\alpha$. First, note that $\mathrm{E}\left(\mathrm{u}_{(2)}\right)-\mathrm{E}\left(\mathrm{u}_{(1)}\right)=\mathrm{E}\left(\max \left[\mathrm{u}_{1}, \mathrm{u}_{2}\right]\right)$ $-\mathrm{E}\left(\min \left[\mathrm{u}_{1}, \mathrm{u}_{2}\right]\right)=\mathrm{E}\left(\max \left[\beta \mathrm{x}_{1}, \beta \mathrm{x}_{2}\right]\right)-\mathrm{E}\left(\min \left[\beta \mathrm{x}_{1}, \beta \mathrm{x}_{2}\right]\right)=\beta \mathrm{E}\left(\max \left[\mathrm{x}_{1}, \mathrm{x}_{2}\right]\right)-\beta \mathrm{E}\left(\min \left[\mathrm{x}_{1}, \mathrm{x}_{2}\right]\right)=$ $\beta\left[\mathrm{E}\left(\mathrm{x}_{(2)}\right)-\mathrm{E}\left(\mathrm{x}_{(1)}\right)\right]$, so that $\mathrm{E}\left(\mathrm{u}_{(2)}\right)-\mathrm{E}\left(\mathrm{u}_{(1)}\right)$ scales linearly with $\beta$. Second, it is straightforward to show that $f_{u}(t)=(1 / \beta) f_{x}(t / \beta)$, which implies:

$\int_{0}^{\beta} f_{u}^{2}(t) d t=\frac{1}{\beta^{2}} \int_{0}^{\beta} f_{x}^{2}\left(\frac{t}{\beta}\right) d t=\frac{1}{\beta} \int_{0}^{1} f_{x}^{2}\left(t^{\prime}\right) d t^{\prime}$, where the last equality uses the substitution $\mathrm{t}^{\prime}=\mathrm{t} / \beta$. This shows that $\mathrm{q}(0)$ scales with $1 / \beta$, canceling the scaling of $\mathrm{E}\left[\mathrm{u}_{(2)}\right)-\mathrm{E}\left(\mathrm{u}_{(1)}\right]$ with $\beta$. Q.E.D.

Proof of Proposition 5 In the classic model, implicit differentiation of the worker's first-order condition, $\mathrm{S} \partial \mathrm{p} / \partial \mathrm{e}_{\mathrm{i}}{ }^{*}-\mathrm{C}^{\prime}\left(\mathrm{e}_{\mathrm{i}}{ }^{*}\right)=0$, reveals that $\partial \mathrm{e}^{*} / \partial \xi>0$ given the properties of $\mathrm{C}(\mathrm{e})$ and satisfaction of the second-order condition. The equilibrium spread is $S^{*}=1 / g(0)$, so $\partial S^{*} / \partial \xi=0$ since $\xi$ does not appear in $\mathrm{g}(0)$. In the market-based model the worker's first-order condition is essentially the same as in the classic model, so a similar argument yields $\partial \mathrm{h}^{*} / \partial \xi>0$. The equilibrium spread is $\mathrm{S}^{*}=\mathrm{V}\left(\mathrm{E}\left[\mathrm{u}_{(2)}\right]-\mathrm{E}\left[\mathrm{u}_{(1)}\right]\right)$, so $\partial \mathrm{S}^{*} / \partial \xi=0$ since $\xi$ does not appear in $\left(\mathrm{E}\left[\mathrm{u}_{(2)}\right]-\right.$ $\left.\mathrm{E}\left[\mathrm{u}_{(1)}\right]\right)$. This establishes (i). In the market-based model, $\mathrm{L}^{*}=\mathrm{V}_{\mathrm{H}}\left(\mathrm{h}^{*}(\mathrm{~V})+0.5\left(\mathrm{E}\left[\mathrm{u}_{(2)}\right]+\mathrm{E}\left[\mathrm{u}_{(1)}\right]\right)\right.$, so $\partial \mathrm{L}^{*} / \partial \xi=\left(\partial \mathrm{L}^{*} / \partial \mathrm{h}^{*}\right)\left(\partial \mathrm{h}^{*} / \partial \xi\right)=\mathrm{V}_{\mathrm{H}} \partial \mathrm{h}^{*} / \partial \xi>0$, establishing (ii). Point (iii) follows from the participation constraint binding in equilibrium, i.e. $\mathrm{L}^{*}-\mathrm{C}\left(\mathrm{e}^{*}\right)=0$, and from the properties of C(e). Q.E.D. 


\section{References}

Acemoglu, D., Pischke, J.S. (1998), "Why Do Firms Train? Theory and evidence," Quarterly Journal of Economics, 113, 79-119.

Ackerberg, Daniel A., and Maristella Botticini. 2002. "Endogenous Matching and the Empirical Determinants of Contract Form." Journal of Political Economy, Vol. 110, No. 3, pp. 564-91.

Aggarwal, Rajesh K., and Andrew A. Samwick. 1999. "The Other Side of the Trade-off: The Impact of Risk on Executive Compensation." Journal of Political Economy, Vol. 107, No. 1, pp. 65-105.

Agrawal, A., C.R. Knoeber, and T. Tsoulouhas (2006), "Are Outsiders Handicapped in CEO Successions?," Journal of Corporate Finance, 12, pp. 619-644.

Allen, Douglas, and Dean Lueck. 1992. "Contract Choice in Modern Agriculture: Cash Rent versus Cropshare.” Journal of Law and Economics, Vol. 35, No. 2, pp. 397-426.

Anderson, Erin, and David C. Schmittlein. 1984. "Integration of the Sales Force: An Empirical Examination.” RAND Journal of Economics, Vol. 15, No. 3, pp. 385-95.

Audas, R., T. Barmby, and J. Treble (2004), "Luck, Effort, and Reward in an Organizational Hierarchy," Journal of Labor Economics, 22, pp. 379-396.

Baker, George, and Bjorn Jorgensen. 2003. "Turbulence, Risk, and Incentives.” Unpublished Working Paper, Harvard University.

Baker, G., M. Gibbs, and B. Holmstrom (1994a), "The Internal Economics of the Firm: Evidence from Personnel Data," Quarterly Journal of Economics, 109, 881-919.

Baker, G., M. Gibbs, and B. Holmstrom (1994b), “The Wage Policy of a Firm,” Quarterly Journal of Economics, 109, 921-955.

Baker, G., M.C. Jensen, and K.J. Murphy (1988), "Compensation and Incentives: Practice vs. Theory," Journal of Finance, 43, 593-616.

Becker, B. and M. Huselid (1992), "The Incentive Effects of Tournament Compensation Systems," Administrative Science Quarterly, 37, pp. 336-350.

Bernhardt, D. (1995), "Strategic Promotion and Compensation," Review of Economic Studies, 62, pp. 315-339.

Bognanno, M.L. (2001), “Corporate Tournaments,” Journal of Labor Economics, 19, pp. 290315. 
Campbell, D. (2008), "Nonfinancial performance measures and promotion-based incentives," Journal of Accounting Research, 46, 297- 332.

Carmichael, L. (1983), "Firm-specific human capital and promotion ladders," Bell Journal of Economics 14, 251-258.

Chan, W. (1996), "External Recruitment Versus Internal Promotion," Journal of Labor Economics, 14, pp. 555-570.

Chang, C., Wang, Y. (1996), "Human capital investment under asymmetric information: the Pigovian conjecture revisited," Journal of Labor Economics, 14, 505-519.

Chen, K.-P., 2003, “Sabotage in Promotion Tournaments". Journal of Law, Economics and Organization, 19, 119-140.

Conyon, Martin J., and Kevin J. Murphy. 2000. "The Prince and the Pauper? CEO Pay in the United States and United Kingdom.” The Economic Journal, Vol. 110, No. 467, pp. 640-71.

Core, John, and Wayne Guay. 1999. "The Use of Equity Grants to Manage Optimal Equity Incentive Levels." Journal of Accounting and Economics, Vol. 28, No. 2, pp. 151-84.

DeVaro, Jed. 2006a. "Strategic Promotion Tournaments and Worker Performance." Strategic Management Journal 27(8): 721-740.

DeVaro, Jed. 2006b. "Internal Promotion Competitions in Firms." The RAND Journal of Economics, vol. 37, pp. 521-541.

DeVaro, Jed, and Dana Brookshire. 2007. "Promotions and Incentives in Nonprofit and ForProfit Organizations." Industrial and Labor Relations Review, 60(3), 311-339.

DeVaro, Jed, and Fidan Ana Kurtulus. 2010. "An Empirical Analysis of Risk, Incentives, and the Delegation of Worker Authority." Industrial and Labor Relations Review, 63(4), 637-657.

DeVaro, Jed, and Hodaka Morita. 2011. "Internal Promotion and External Recruitment: A Theoretical and Empirical Analysis” Mimeo: University of New South Wales.

DeVaro, Jed, and Michael Waldman. 2011. "The Signaling Role of Promotions: Further Theory and Empirical Evidence" Forthcoming in Journal of Labor Economics.

DeVaro, Jed, and Suraj Prasad. 2011. "Delegation and Incentives: A Tradeoff Between Exploration and Exploitation” Mimeo: University of New South Wales.

Drago, Robert, and Gerald Garvey. 1998. "Incentives for Helping on the Job: Theory and Evidence," Journal of Labor Economics 16(1), 1-25.

Ehrenberg, R.G. and M.L. Bognanno (1990a), “Do Tournaments Have Incentive Effects?," Journal of Political Economy, 98, pp. 1307-1324. 
Ehrenberg, R.G. and M.L. Bognanno (1990b), "The Incentive Effects of Tournaments Revisited: Evidence from the European PGA Tour," Industrial \& Labor Relations Review, 43, pp. 74S-88S.

Eriksson, T. (1999), "Executive Compensation and Tournament Theory," Journal of Labor Economics, 17, pp. 262-280.

Fairburn, James A. and James M. Malcomson, 2001. "Performance, Promotion, and the Peter Principle," Review of Economic Studies, 68(1), 45-66.

Foss, Nicolai J., and Keld Laursen. 2005. "Performance Pay, Delegation and Multitasking Under Uncertainty and Innovativeness: An Empirical Investigation." Journal of Economic Behavior and Organization, Vol. 58, No. 2, pp. 246-76.

Garen, John E. 1994. "Executive Compensation and Principal-Agent Theory." Journal of Political Economy, Vol. 102, No. 6, pp. 1175-99.

Garvey, G. and P.L. Swan (1992), "Managerial Objectives, Capital Structure, and the Provision of Work Incentives," Journal of Labor Economics, 10, pp. 357-379.

Gerhart, B. and G. Milkovich (1989), "Salaries, Salary Growth, and Promotions of Men and Women in a Large Private Firm," in R. Michael, H. Hartmann, and B. O'Farrell, eds., Pay Equity: Empirical Inquiries, (National Academy Press, Washington D.C.), 23-48.

Ghosh, S. and M. Waldman (2010), "Standard Promotion Practices Versus Up-or-Out Contracts," Rand Journal of Economics, 41, pp. 301-325.

Gibbons, Robert and Michael Waldman. 1999a. A theory of wage and promotion dynamics inside firms. Quarterly Journal of Economics 114, no. 4:1321-58.

Gibbons, R. and M. Waldman (1999b), "Careers in Organizations: Theory and Evidence," in O.Ashenfelter and D. Card, eds., Handbook of Labor Economics, Volume 3, (North-Holland: Amsterdam, The Netherlands), 2373-2437.

Gibbons, Robert and Michael Waldman. 2006. Enriching a theory of wage and promotion dynamics inside firms. Journal of Labor Economics 24, no. 1:59-107.

Gibbs, M. (1994), "Testing Tournaments? An Appraisal of the Theory and Evidence", Labor Law Journal.

Gibbs, M. (1995), "Incentive Compensation in a Corporate Hierarchy," Journal of Accounting and Economics, 19, pp. 247-277.

Gibbs, M. (1996), "Promotions and Incentives." Unpublished working paper, University of Chicago. 
Golan, L. (2005), "Counteroffers and Efficiency in Labor Markets with Asymmetric Information," Journal of Labor Economics, 23, pp. 373-393.

Green, J.R. and N. Stokey (1983), “A Comparison of Tournaments and Contracts,” Journal of Political Economy, 91, pp. 349-364.

Greenwald, B. (1986), “Adverse Selection in the Labour Market," Review of Economic Studies, $53,325-347$.

Gürtler, Oliver (2008), "On Sabotage in Collective Tournaments.” Journal of Mathematical Economics 44, pp. 383-393.

Holmström, Bengt. 1979. "Moral Hazard and Observability," Bell Journal of Economics, Vol. 10, No. 1, pp. 74-91.

John, George and Barton Weitz. 1989. "Salesforce Compensation: An Empirical Investigation of Factors Related to Use of Salary Versus Incentive Compensation.” Journal of Marketing Research, Vol. 26, No. 1, pp. 1-14.

Kawasaki, Seiichi and John McMillan. 1987. "The Design of Contracts: Evidence from Japanese Subcontracting." Journal of the Japanese and International Economies, 1(3), pp. 327-49.

Knoeber, C.R. and W.N. Thurman (1994), "Testing the Theory of Tournaments: An Empirical Analysis of Broiler Production," Journal of Labor Economics, 12, pp. 155-179.

Konrad, K.A., (2000), “Sabotage in Rent-Seeking Contests," Journal of Law, Economics and Organization, 16, 155-165.

Kräkel, M., (2005) "Helping and Sabotaging in Tournaments.” International Game Theory Review, 7, 211-228.

Lafontaine, Francine. 1992. “Agency Theory and Franchising: Some Empirical Results.” RAND Journal of Economics, Vol. 23, No. 2, pp. 263-83.

Lambert, Richard A., and David F. Larcker. 1987. "An Analysis of the use of Accounting and Market Measures of Performance in Executive Compensation Contracts." Journal of Accounting Research, Vol. 25 (Supplement), pp. 85-125.

Lambert, R., D. Larcker, and K. Weigelt (1993), “The Structure of Organizational Incentives,” Administrative Science Quarterly, 38, pp. 438-461.

Lazear, Edward P. and Sherwin Rosen. 1981. "Rank-Order Tournaments as Optimum Labor Contracts.” Journal of Political Economy, vol. 89, pp. 841-864. 
Lazear, Edward. 1986. "Raids and offer matching." Research in Labor Economics 8, part A:14165 .

Lazear, E. (1989), "Pay Equality and Industrial Politics," Journal of Political Economy, 97, pp. 561-580.

Lazear, E. (1992), “The Job as a Concept,” in W. Bruns, ed., Performance Measurement, Evaluations, and Incentives (Harvard University Press: Boston, MA), 183-215.

Lazear, E. (1999), "Personnel Economics: Past Lessons and Future Directions," Journal of Labor Economics, 17, pp. 199-236.

Lazear, E. and P. Oyer (2010), "Personnel Economics," in R. Gibbons and J. Roberts, eds., Handbook of Organizational Economics, Forthcoming.

Leffler, Keith B., and Randal R. Rucker. 1991. "Transactions Costs and the Efficient Organization of Production: A Study of Timber-Harvesting Contracts." Journal of Political Economy, Vol. 99, No. 5, pp. 1060-87.

Levy, Armando, and Tomislav Vukina. 2004. "The League Composition Effect in Tournaments with Heterogeneous Players: An Empirical Analysis of Broiler Contracts." Journal of Labor Economics, Vol. 22, No. 2, pp. 353-377.

MacLeod, W.B. and J.M. Malcomson (1988), "Reputation and Hierarchy in Dynamic Models of Employment," Journal of Political Economy, 96, pp. 832-854.

Main, B., C. O’Reilly III, and J. Wade (1993), “Top Executve Pay: Tournaments or Teamwork?," Journal of Labor Economics, 11, pp. 606-628.

Malcomson, J.M. (1984), “Work Incentives, Hierarchy, and Internal Labor Markets," Journal of Political Economy, 92, pp. 486-507.

Martin, Robert E. 1988. "Franchising and Risk Management." The American Economic Review, Vol. 78, No. 5, pp. 954-68.

McCue, K. (1996), "Promotions and Wage Growth," Journal of Labor Economics, 14, 175209.

Mengistae, Taye, and Lixin Colin Xu. 2004. "Agency Theory and Executive Compensation: The Case of Chinese State-Owned Enterprises." Journal of Labor Economics, Vol. 22, No. 3, pp. 615-37.

Meyer, M.A. (1991), "Learning from Coarse Information: Biased Contests and Career Profiles," Review of Economic Studies, 58, pp. 15-41.

Meyer, M.A. (1992), "Biased Contests and Moral Hazard: Implications for Career Profiles,” 
Annales d'Economic et de Statistique, 25/26, pp. 165-187.

Meyer, Margaret, Paul R. Milgrom, and D. John Roberts, 1992. "Organizational Prospects, Influence Costs, and Ownership Changes," Journal of Economics and Management Strategy, 1(1), 9-35.

Milgrom, P. and S. Oster (1987), "Job Discrimination, Market Forces, and the Invisibility Hypothesis," Quarterly Journal of Economics, 102, 453-476.

Milgrom, Paul R. and D. John Roberts, 1988. "An Economic Approach to Influence Activities in Organizations,” American Journal of Sociology, 94(supplement), S154-S179.

Mookherjee, D. (1984), "Optimal Incentive Schemes with Many Agents," Review of Economic Studies, 51, pp. 433-446.

Murphy, K.J. (1985), "Corporate Performance and Managerial Remuneration: An Empirical Analysis," Journal of Accounting and Economics, 7, 11-42.

Nalebuff, B.J. and J.E. Stiglitz (1983), "Prizes and Incentives: Towards a General Theory of Compensation and Competition," Bell Journal of Economics, 14, pp. 21-43.

Norton, Seth W. 1988. "An Empirical Look at Franchising as an Organizational Form." Journal of Business, Vol. 61, No. 2, pp. 197-218.

O'Keeffe, M., W.K. Viscusi, and R.J. Zeckhauser (1984), "Economic Contests: Comparative Reward Schemes," Journal of Labor Economics, 2, pp. 27-56.

O’Reilly III, C., B. Main, and G. Crystal (1988), "CEO Compensation as Tournament and Social Comparison: A Tale of Two Theories," Administrative Science Quarterly, 33, pp. 257-274.

Owan, H. (2004), "Promotion, Turnover, Earnings, and Firm-Sponsored Training," Journal of Labor Economics, 22, pp. 955-978.

Oyer, Paul. 2004. "Why Do Firms Use Incentives That Have No Incentive Effects?" Journal of Finance, Vol. LIX, No. 4, pp. 1619-49.

Oyer, Paul, and Scott Schaefer. 2005. "Why Do Some Firms Give Stock Options to All Employees?: An Empirical Examination of Alternative Theories." Journal of Financial Economics, Vol. 76, No. 1, pp. 99-133.

Prendergast, C. (1993), "The Role of Promotion in Inducing Specific Human Capital Acquisition," Quarterly Journal of Economics, 108, pp. 523 - 534.

Prendergast, C. (1999), “The Provision of Incentives in Firms," Journal of Economic Literature, 37, pp. 7-63. 
Prendergast, C. (2000): "What trade-off of risk and incentives?" American Economic Review Papers and Proceedings, 90, 421-425.

Prendergast, Canice. 2002. "The Tenuous Trade-off Between Risk and Incentives.” Journal of Political Economy, Vol. 110, No. 5, pp. 1071-1102.

Raith, Michael. 2003. "Competition, Risk, and Managerial Incentives.” American Economic Review, Vol. 93, No. 4, pp. 1425-36.

Raith, Michael. 2008. "Specific Knowledge and Performance Measurement." RAND Journal of Economics, Vol. 39, No. 4, pp. 1059-79.

Rantakari, Heikki. 2008. “On the Role of Uncertainty in the Risk-Incentives Tradeoff”, The B.E. Journal of Theoretical Economics (Topics), 8(1).

Rao, C. H. Hanumantha. 1971. "Uncertainty, Entrepreneurship, and Sharecropping in India." Journal of Political Economy, Vol. 79, No. 3, pp. 578-95.

Ricart i Costa, J. (1988), "Managerial Task Assignments and Promotions," Econometrica, 56, pp. 449-466.

Rosen, S. (1982), “Authority, Control, and the Distribution of Earnings," Bell Journal of Economics, 13, 311-323.

Rosen, Sherwin. 1986. "Prizes and Incentives in Elimination Tournaments." American Economic Review, Vol. 76, 701-716.

Schaefer, Scott, 1998. "Influence Costs, Structural Inertia, and Organizational Change,' Journal of Economics and Management Strategy, 7(2), 237-263.

Serfes, Konstantinos. 2005. "Risk Sharing vs. Incentives: Contract Design Under Two-sided Heterogeneity." Economics Letters, Vol. 88, No. 3, pp. 343-49.

Shavell, Steven M. 1979. "Risk Sharing and Incentives in the Principal and Agent Relationship." Bell Journal of Economics, Vol. 10, No. 1, pp. 55-73.

Tsoulouhas, T., C.R. Knoeber, and A. Agrawal (2007), "Contests to Become CEO: Incentives, Selection and Handicaps," Economic Theory, 30, pp. 195-221.

Waldman, M. (1984a). "Job Assignments, Signaling and Efficiency.” Rand Journal of Economics. Vol. 15, 255-270.

Waldman, M. (1984b), "Worker Allocation, Hierarchies, and the Wage Distribution," Review of Economic Studies, 51, 95-109.

Waldman, M. (1990), "Up-or-out-contracts: a Signalling Perspective," Journal of Labor Economics, 8, 230-250. 
Waldman, M. (2003), "Ex Ante Versus Ex Post Optimal Promotion Rules: The Case of Internal Promotion," Economic Inquiry, 41, pp. 27-41.

Waldman, M. (2010), “Theory and Evidence in Internal Labor Markets”, in R. Gibbons and J.Roberts, eds., Handbook of Organizational Economics.

Waldman, Michael. 2011. "Classic Promotion Tournaments versus Market-Based Tournaments", working paper, Cornell University.

Wulf, Julie. 2007. “Authority, Risk, and Performance Incentives: Evidence from Division Manager Positions Inside Firms.” Journal of Industrial Economics, 55(1), pp. 169-96.

Yermack, David. 1995. “Do Corporations Award CEO Stock Options Effectively.” Journal of Financial Economics, Vol. 39, No. 2, pp. 237-69.

Zabojnik, Jan. 1996. "Pay-Performance Sensitivity and Production Uncertainty. Economic Letters, Vol. 53, No. 3, pp. 291-96.

Zábojník, Ján and Dan Bernhardt. 2001. "Corporate Tournaments, Human Capital Acquisition, and the Firm Size-Wage Relation.” Review of Economic Studies, vol. 68, pp. 693-716.

Zábojník, J. (2011), "Promotion Tournaments in Market Equilibrium,” Forthcoming Economic Theory. 


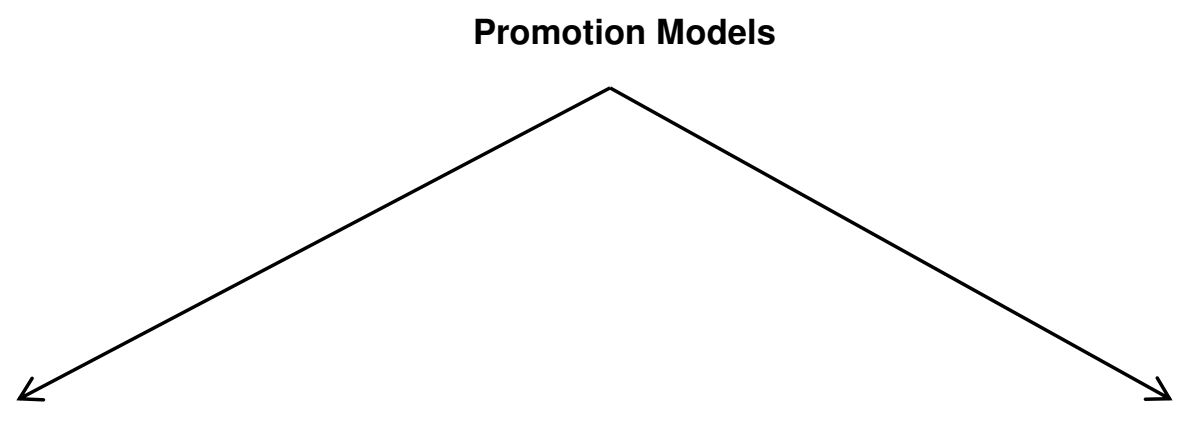

\section{Internal Promotion Competitions}

(fixed managerial job slots)

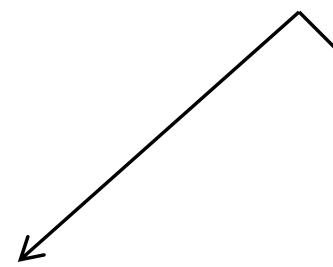

Classic Tournaments

(firm commits to wage spreads ex ante)

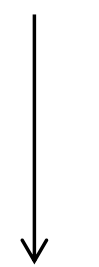

Workers

Choose Effort

Workers

\section{Performance Standards}

(flexible managerial job slots)

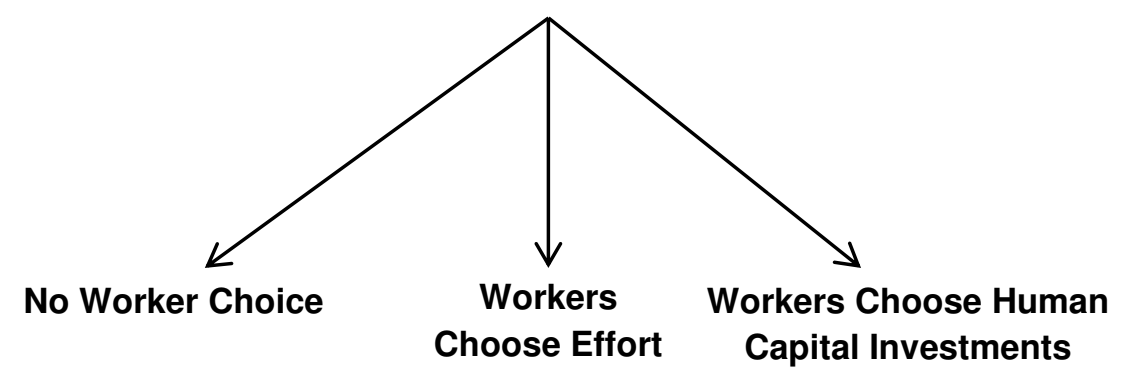

(wage spreads arise ex post from competing wage bids)

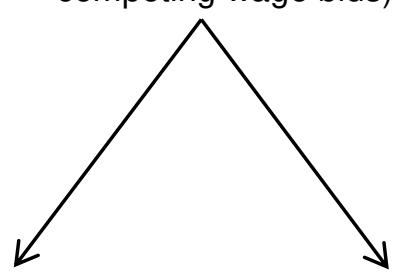

Workers Choose Human

Choose Effort Capital Investments 